\title{
La representación política de las personas de origen inmigrante en España e Italia*
}

\author{
Daniela Vintila \\ Université de Liège. Centre d'Études de l'Ethnicité et des Migrations (CEDEM) \\ Daniela.Vintila@uliege.be
}

\section{Laura Morales}

Sciences Po, Centre d'études européennes et de politique comparée (CEE), CNRS, París, Francia**

laura.morales@sciencespo.fr

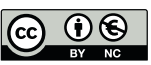

Recepción: 16-10-2017

Aceptación: 05-04-2018

Publicación: 12-07-2018

\section{Resumen}

En los últimos veinte años, las sociedades de España e Italia han experimentado un cambio demográfico muy notable debido a flujos migratorios de alta intensidad. Desde principios de la década de 1990, la población extranjera se multiplicó por cinco en ambos países y en 2010 alcanzó el 12 y el 6 por ciento, respectivamente, del conjunto poblacional (INE, 2015; ISTAT, 2015). En ambos casos, dicho fenómeno migratorio plantea nuevos desafíos de representación democrática, dado que, en un periodo muy corto de tiempo, ha generado un gran caudal de nuevos residentes con expectativas legítimas de hacer oír su voz en el proceso de toma de decisiones. Sin embargo, el aumento del número de inmigrantes residentes en España e Italia también coincidió con un período en el que la opinión pública empezó a mostrar mayor preocupación por la inmigración, lo que provocó actitudes negativas cada vez más visibles hacia los colectivos inmigrantes en ambos países. Este artículo analiza en qué medida la presión migratoria y el cambio actitudinal hacia los inmigrantes en España e Italia pueden ayudarnos a comprender mejor las estrategias de los partidos a la hora de facilitar el acceso de este colectivo a cargos electos en los parlamentos nacionales. Haciendo

* Agradecimientos. Este artículo se ha desarrollado en el marco del proyecto internacional Pathways to Power: The Political Representation of Citizens of Immigrant Origin in Seven European Democracies (PATHWAYS, http://pathways.eu/) financiado por ANR (Francia), DFG (Alemania), ESRC (Reino Unido) y NWO (Holanda) a través del programa Open Research Area (ORA+). Las autoras agradecen la subvención del Consejo de Investigaciones Económicas y Sociales (Economic and Social Research Council, ESRC) del Reino Unido que financió directamente la realización del estudio para los casos de España e Italia. Esta investigación no habría sido posible sin dicha financiación. El ESRC no asume ninguna responsabilidad en relación a las conclusiones de este artículo.

** Sciences Po es miembro de la Universidad Sorbona París Cité (USPC). 
uso de una base de datos única que incluye información sobre el perfil sociodemográfico y político de todos los diputados y diputadas en ambos países desde 1990 hasta la actualidad, nuestro estudio contribuye a avanzar en el conocimiento sobre las dinámicas que favorecen y que dificultan la representación política de los inmigrantes en estos dos países del sur de Europa.

Palabras clave: inmigración; parlamentos; diputados y diputadas; partidos políticos; opinión pública

\section{Abstract. Political representation of citizens of immigrant origin in Spain and Italy}

In the 1990 s and the 2000s, Spain and Italy experienced a considerable growth in immigration. In just two decades, the foreign population has multiplied more than fivefold in both countries and by 2010 accounted for 12 and 6 per cent of the total population, respectively (INE, 2015; ISTAT, 2015). This demographic change has put pressure on the democratic representative system of both countries, with large numbers of new residents wishing to have a voice in the direction of collective affairs. Yet, at the same time, public opinion has become increasingly concerned about immigration and immigrants' integration in both countries, with attitudes towards immigrants becoming increasingly negative in both. This article examines how these competing pressures can help us better understand the strategies of political parties in relation to the incorporation of citizens of immigrant origin into elected office in the national parliaments of both countries. Drawing on an original and unique dataset on the socio-demographic characteristics and political profiles of all national MPs elected in Spain and Italy since the beginning of the 1990s, this study aims at examining the dynamics which encourage or hinder the political representation of citizens of immigrant origin in these two Southern European countries.

Keywords: immigration; parliaments; MPs; political parties; public opinion

\begin{aligned} & \multicolumn{2}{c}{ Sumario } \\ & 1. Introducción 3. Datos y fuentes \\ & 2. Estableciendo la estructura 4. La representación descriptiva \\ & de «demandas» y «costes» de los inmigrantes en España e Italia \\ & de la representación política de los 5. Conclusiones \\ & inmigrantes Referencias bibliográficas \end{aligned}

\section{Introducción}

El panorama social de la mayoría de los países europeos ha cambiado sustancialmente a lo largo del último siglo. Durante y después de la Segunda Guerra Mundial, un número considerable de refugiados cruzaron Europa en búsqueda de paz y refugio. Además de los movimientos de refugiados, desde principios de los años cincuenta hasta bien entrada la década de 1970, varios países como Alemania, Bélgica, Francia, los Países Bajos, Reino Unido o Suiza implementaron programas de reclutamiento de trabajadores invitados (guestworkers), cuyo 
objetivo era contribuir al crecimiento económico e industrial que se produjo después de la guerra. Algunos de estos programas estaban orientados también hacia trabajadores procedentes de España e Italia, y cientos de miles de ellos emigraron a otros países europeos o a otros continentes (Colombo y Sciortino, 2004; Veikou y Triandafyllidou, 2001). En Italia, el saldo migratorio fue negativo hasta 1987, con cerca de 3.700 .000 emigrantes entre 1960 y 1975. España no comenzó a registrar una migración neta positiva hasta 1991, con importantes flujos de emigración hasta la década de 1970 y cerca de 1.300 .000 emigrantes entre 1960 y 1975 (Venturini, 2004).

La composición demográfica de estos dos países del sur de Europa comenzó a cambiar durante los años ochenta, con flujos moderados de inmigrantes procedentes de Marruecos, Filipinas o la República Dominicana. Las entradas de personas de origen extranjero aumentaron considerablemente desde finales de la década de 1990, lo que produjo un cambio demográfico de proporciones impresionantes, particularmente en el caso español. En tan solo veinte años, la población extranjera se multiplicó por cinco en ambos países. Alcanzó el 6 por ciento del total de habitantes en Italia y el 12 por ciento en España a finales de la década del 2000 (INE, 2015; ISTAT, 2015). Entre 2002 y 2008 , la magnitud del fenómeno migratorio fue tan intensa que cerca de 600.000 personas entraron en España cada año, con un máximo de 900.000 entradas en 2007. Italia experimentó flujos migratorios más moderados, con una media de 360.000 entradas anuales entre 2002 y 2008 y un máximo de casi 500.000 en 2007 y 2008 (OECD, 2015). Sin embargo, mientras que en España dichas cifras también incluyen a los inmigrantes irregulares, en Italia se refieren exclusivamente a las entradas de inmigrantes con residencia legal, puesto que las estadísticas oficiales italianas no registran los flujos irregulares. A principios de 2015, más de 6 millones de personas nacidas en el extranjero residían en España (INE, 2015), mientras que Italia registraba cerca de 5 millones de inmigrantes regulares (ISTAT, 2015).

Estos cambios demográficos de tan alta intensidad hacen que España e Italia sean estudios de caso muy interesantes a la hora de analizar las respuestas de los partidos políticos a la magnitud del cambio social y las expectativas de una inclusión gradual de las personas de origen inmigrante (de ahora en adelante, POI) en el sistema político. Pese a ello, la integración política de los inmigrantes en España y en Italia no ha sido objeto de estudio hasta hace poco, particularmente en lo relativo a ciertas dimensiones. La mayoría de los análisis previos se han centrado fundamentalmente en la participación política de los extranjeros residentes en estos países, ya sea desde un punto de vista jurídico, centrándose en el acceso a derechos electorales ${ }^{1}$ (véase Santolaya y

1. En relación con la legislación que permite a los extranjeros acceder a derechos electorales en España y en Italia, cabe destacar que, en ambos países, la institucionalización del estatuto de ciudadanía europea en el Tratado de Maastricht llevó al reconocimiento del derecho de sufragio activo y pasivo en elecciones al Parlamento Europeo y en elecciones municipales para los extranjeros procedentes de algún otro estado miembro de la Unión Europea. Mientras que en Italia solo los extranjeros comunitarios pueden votar y presentarse como 
Díaz Crego, 2008; Moya Malapeira, 2010; Tintori, 2013), o desde un punto de vista empírico, al destacar los bajos niveles de participación electoral entre los extranjeros con derecho a voto en elecciones municipales organizadas en ambos países (véase Méndez Lago, 2010; Morales et al., 2010; Morales y San Martín, 2011; Vintila, 2015). Algunos estudios han abarcado también los modos de participación política no electoral (por ejemplo: Morales et al., 2008; Morales y Giugni, 2011).

Sin embargo, hay muy pocos estudios centrados exclusivamente en el análisis de la representación política de los colectivos inmigrantes residentes en España e Italia. Por otra parte, los trabajos previos sobre representación política se centran exclusivamente en las vías de acceso de las POI a la política municipal (Ciornei, 2014; Pérez-Nievas et al., 2014), con algunos estudios centrados en el caso específico de los extranjeros comunitarios (Méndez Lago, 2010). Solo Zapata-Barrero y Burchianti (2014) han desarrollado un estudio de caso sobre la representación política descriptiva de los inmigrantes a nivel nacional y autonómico en España. Sin embargo, el proceso de recopilación de datos que llevan a cabo es más impresionista que sistemático, y aunque las cifras que encuentran también apuntan hacia una pauta de infrarrepresentación del colectivo inmigrante, parecen más altas que las que documentamos en nuestro estudio.

Siguiendo la literatura sobre representación política descriptiva (Pitkin, 1967; Bird, Saalfeld y Wüst, 2011), el rápido cambio demográfico en España e Italia haría pensar que los partidos políticos responderían de manera gradual a la inclusión política de este sector específico de la población. Por otra parte, el hecho de que las llegadas de inmigrantes a España e Italia se hayan intensificado solo durante las últimas décadas, que únicamente los inmigrantes naturalizados puedan votar y presentarse como candidatos en elecciones generales y que el proceso de naturalización en ambos países requiera un largo período de residencia previa no ha creado un entorno especialmente favorable para el acceso de los inmigrantes a cargos electos en los parlamentos nacionales de estos países. Es más, si a esta configuración institucional y demográfica le añadimos el hecho de que el proceso de reclutamiento político es generalmente lento (lo que también podría obstaculizar la nominación de candidatos y candidatas inmigrantes), resulta razonable esperar que el acceso de los ciudadanos y de las ciudadanas de origen inmigrante a cargos electos en España y en Italia haya

candidatos (y esto únicamente para elecciones europeas y locales), en España, la existencia de un precepto constitucional que reconoce el derecho de voto de los extranjeros extracomunitarios en base a acuerdos de reciprocidad con terceros países permite que los residentes no nacionales procedentes de Noruega, Bolivia, Perú, Ecuador, Chile, Colombia, República de Corea, Paraguay, Islandia, Nueva Zelanda, Cabo Verde y Trinidad y Tobago puedan actualmente votar en elecciones municipales en España. Sin embargo, dichos convenios de reciprocidad solo contemplan el sufragio activo para elecciones municipales, manteniéndose el sufragio pasivo condicionado a la adquisición de la nacionalidad española. Por otra parte, el proceso de naturalización sigue condicionando también el acceso a los derechos de sufragio activo y pasivo en las elecciones autonómicas o regionales y generales en ambos países. 
sido bastante restringido y relativamente reciente (particularmente desde la mitad de la primera década del 2000).

Pese a ello, estudios previos también han demostrado que la existencia de un número reducido de potenciales candidatos y candidatas inmigrantes puede no ser un obstáculo infranqueable para la representación política de dicho colectivo si los partidos muestran una voluntad explícita de incluir a la población inmigrante en instituciones representativas (Claro da Fonseca, 2011). En este sentido, podemos señalar una serie de ventajas y desventajas para los partidos que deciden presentar candidatos y candidatas inmigrantes (Celis et al., 2013). Por un lado, la inclusión de POI en las listas electorales podría ser un mecanismo mediante el cual los partidos indicaran al electorado su preocupación por los procesos de cambio social, demostrando así que son inclusivos $\mathrm{y}$ «modernos». Es más, la nominación de POI también puede perfilarse como estrategia electoral para atraer un nuevo nicho de votantes - el electorado inmigrante- cuyas identificaciones partidistas siguen siendo bastante maleables. No obstante, incluir candidatos y candidatas inmigrantes también puede ser una decisión arriesgada, ya que podría dar lugar a conflictos internos dentro del partido, debido al desplazamiento de candidatos y candidatas en las listas. Junto a ello, si la opinión pública tampoco es particularmente favorable a la inmigración, la decisión de nominar POI podría llevar incluso a una importante pérdida de votos.

Por esta razón, el presente estudio también analiza las tendencias de la opinión pública en España e Italia en torno a la inmigración. Como mostraremos seguidamente, la inmigración se ha convertido en un tema relevante en los dos países a lo largo de la primera década del siglo XXI, con picos de atención en 2006. En ambos casos, las actitudes negativas hacia la inmigración han resultado cada vez más visibles, particularmente en el caso italiano. Pese a ello, el apoyo al reconocimiento del derecho de voto a los extranjeros en elecciones municipales y generales sigue siendo bastante generalizado en ambos países, e incluso más alto en Italia en comparación con España.

Este panorama general de fuerte cambio social y mensajes ambivalentes en torno a la inmigración por parte de la opinión pública nos lleva a esperar que los partidos españoles e italianos hayan reaccionado lentamente con respecto a la integración política de las POI. Si bien cabe esperar que dicha reacción sea más destacable a partir de mediados de la primera década del siglo XXI, con la inclusión de más POI en las listas electorales, también es razonable esperar que este proceso de nominación de las POI sea fundamentalmente simbólico, como gesto de adaptación a los nuevos tiempos. Por lo tanto, partimos de la hipótesis de que las POI estarán presentes en los parlamentos de ambos países, pero en proporción inferior a su peso poblacional.

Segundo, teniendo en cuenta los flujos migratorios más intensos hacia España, el hecho de que gran parte de estos flujos estén compuestos por latinoamericanos - que tienen un acceso facilitado a la nacionalidad-, y que los españoles generalmente hayan mostrado actitudes más favorables hacia la inmigración que los italianos, cabría esperar que los niveles de representación 
política de las POI sean algo mayores en España que en Italia. Tercero, dada la intensificación de las actitudes negativas hacia la inmigración en ambos países, partimos de la hipótesis de que los partidos preferirán nominar candidatos y candidatas «invisibles» en vez de minorías «visibles» o fácilmente identificables, para evitar reacciones negativas por parte del público. Por esta razón, cabe esperar que las POI procedentes de la UE o de Albania sean quienes obtengan representación en el Parlamento italiano, y que los latinoamericanos y las POI procedentes de otros países de la UE tengan mayor presencia en el Congreso de los Diputados español. Finalmente, dados los pocos incentivos que tienen los partidos españoles e italianos para incluir candidaturas de inmigrantes en sus listas, partimos de la hipótesis de que dichas nominaciones simbólicas serán más frecuentes entre los partidos de centroizquierda que entre los partidos de centroderecha.

Siguiendo estas hipótesis, el artículo está estructurado de la siguiente forma. La próxima sección analiza los flujos migratorios y las tendencias de opinión pública en torno a la inmigración en España e Italia, con el fin de entender mejor la «demanda» y los "costes» de la representación política descriptiva de las POI. La tercera sección presenta los datos recogidos sobre diputados y diputadas de origen inmigrante en parlamentos nacionales y autonómicos en ambos países desde 1990 en adelante. Tal como esperábamos, el análisis empírico demuestra que los niveles de representación política de las POI durante las últimas décadas han sido bastante reducidos en ambos países. Es más, los porcentajes de diputados y diputadas de origen inmigrante son bastante similares en España y en Italia, pese a nuestra hipótesis inicial de que el contexto español fuera más favorable que el italiano a la hora de asegurar la presencia de las POI en las asambleas legislativas. Nuestros resultados también confirman que la mayoría de los diputados y de las diputadas inmigrantes son minorías «invisibles», y únicamente en Italia hemos identificado un porcentaje más elevado de representantes que pertenecen a colectivos más «visibles». Finalmente, el estudio demuestra que no hay diferencias significativas entre los partidos de centroizquierda y los de centroderecha en lo que se refiere a la inclusión de las POI. Como argumentaremos, el sistema electoral en España y en Italia no ha sido particularmente propicio a la inclusión de las POI en las listas electorales, y los principales partidos en ambos países tampoco han mostrado gran interés por incluir estos colectivos en sus organizaciones internas.

\section{Estableciendo la estructura de «demandas» $\mathrm{y}$ «costes» de la representación política de los inmigrantes}

\subsection{Las pautas migratorias hacia Italia y España}

Los gráficos 1 y 2 muestran la evolución de los flujos migratorios y del número de extranjeros residentes en España e Italia, con estadísticas provenientes de la OECD y de Eurostat. En ambos países se observa un aumento acelerado de las llegadas de inmigrantes desde principios de la década del 2000, cuyo número 
Gráfico 1. Flujos de población extranjera hacia España e Italia (desde 1990, miles)

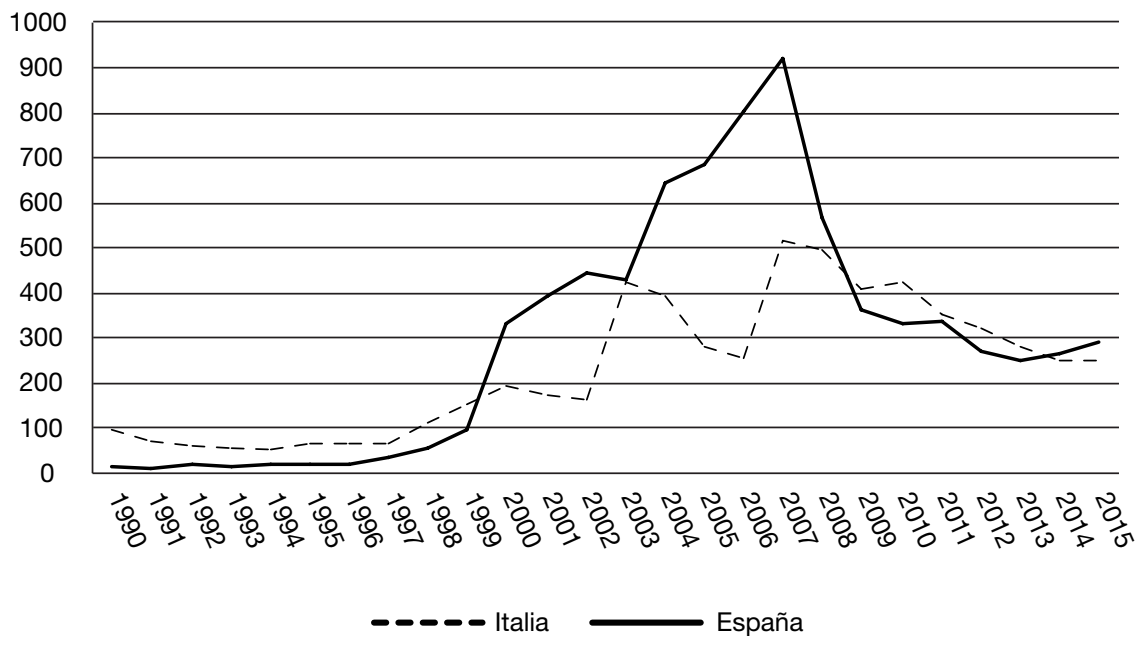

Fuente: elaboración propia a partir de datos de la International Migration Database (OECD, 2015): flujos de población extranjera por nacionalidad (varios años).

Gráfico 2. Evolución del número de personas de nacionalidad extranjera residentes en España e Italia (desde 1998)

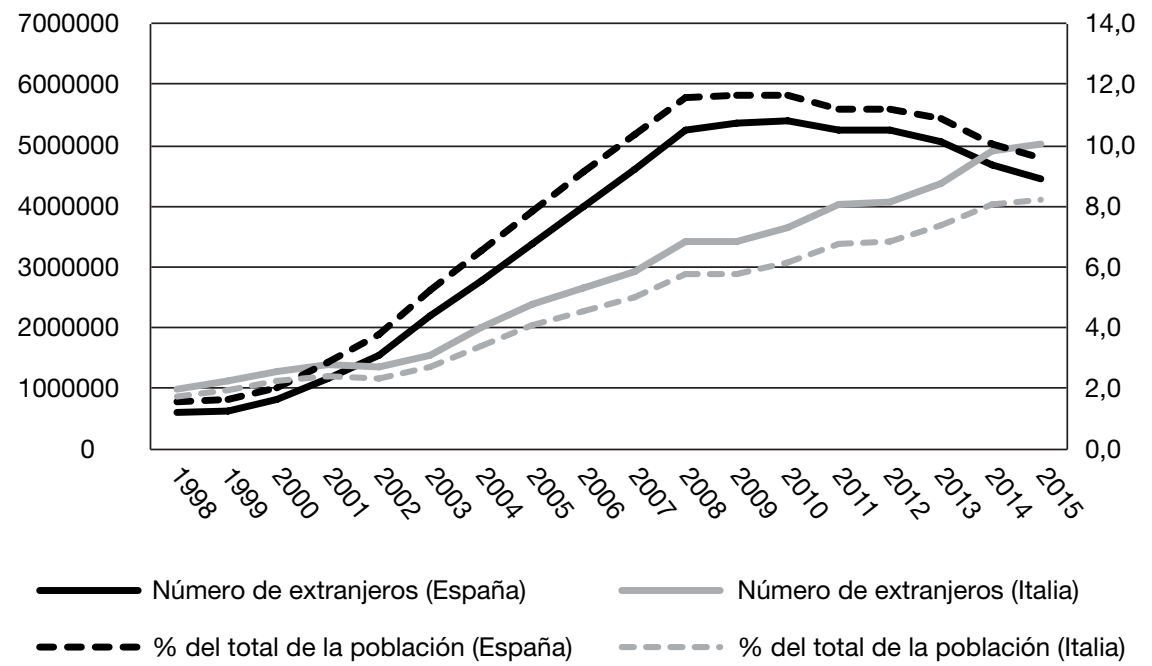

Fuente: elaboración propia a partir de datos de Eurostat (2015): Población a 1 de enero por grupo de edad, género y nacionalidad (varios años). 
alcanzó el pico más alto en 2007. A partir de ese año, los flujos migratorios hacia España e Italia disminuyeron de forma notable, aunque siguieron manteniéndose en niveles muy elevados en comparación con otros países europeos. La magnitud sin precedentes de los flujos migratorios también dio lugar a un aumento sostenido del número de extranjeros residentes en ambos países (gráfico 2). Entre 1990 y 2014, dicho número de extranjeros residentes se multiplicó por 5 en Italia y por 7 en España. Quince años después del comienzo de los flujos de mayor intensidad, en 2015, entre 4 y 5 millones de extranjeros residían en cada uno de estos dos países. Representaban el 8 por ciento de la población en Italia y el 10 por ciento en España (Eurostat, 2015). Por lo tanto, a la vista del peso demográfico considerable de la población inmigrante en ambos países, sus demandas de inclusión política son no solo legítimas, sino también bastante razonables.

Sin embargo, la composición y la procedencia de estos flujos migratorios también es relevante para asegurar una "demanda» coherente de representación política de las POI. En ambos países, el grueso de la población de origen extranjero está compuesto por inmigrantes laborales que trabajan especialmente en sectores como la agricultura, la construcción, la industria o los servicios domésticos (Venturini, 2004; Cebolla y González, 2008). Hasta mediados de la primera década del siglo XXI, la gran mayoría de estos trabajadores inmigrantes procedían de países extracomunitarios, fundamentalmente de África y de América Latina. La inmigración de carácter laboral se intensificó aún más con la ampliación de la UE en 2004 y 2007, lo que incentivó las llegadas de trabajadores procedentes de los nuevos estados miembros, especialmente Rumanía, Polonia y Bulgaria.

En España, la mayoría de los extranjeros son extracomunitarios y proceden de América Latina o de África (casi el 22 por ciento de todos los extranjeros en cada caso), pero también de Asia (el 8 por ciento). Aunque los extranjeros procedentes de la UE15 forman una parte sustancial del número de inmigrantes residentes (un 20 por ciento de todos los extranjeros residentes en España en 2015) — debido al elevado número de inmigrantes británicos, franceses, escandinavos y alemanes con elevados recursos económicos que residen en España (Janoschka, 2010)—, los flujos más recientes proceden de los nuevos estados miembros de la UE, especialmente rumanos y búlgaros. En 2015, los rumanos y los marroquíes eran los colectivos extranjeros más numerosos. Cada uno de ellos representaba el 16 por ciento de todos los extranjeros residentes en España (INE, 2015).

En cambio, casi la mitad de la población extranjera residente en Italia en 2015 estaba formada por personas procedentes de otros países europeos. Al igual que en España, los rumanos representaban el colectivo más numeroso (el 23 por ciento de todos los extranjeros), seguidos de los albaneses (el 10 por ciento), los marroquíes (el 9 por ciento) y los chinos (el 5 por ciento) (ISTAT, 2015).

No obstante, estas cifras se refieren solo a extranjeros y la población inmigrante es aún mayor, dado que también incluye a los inmigrantes ya naturalizados, así como sus descendientes nacidos en estos países, algunos ya con la 
Gráfico 3. Número de inmigrantes naturalizados en España e Italia (desde 1991)

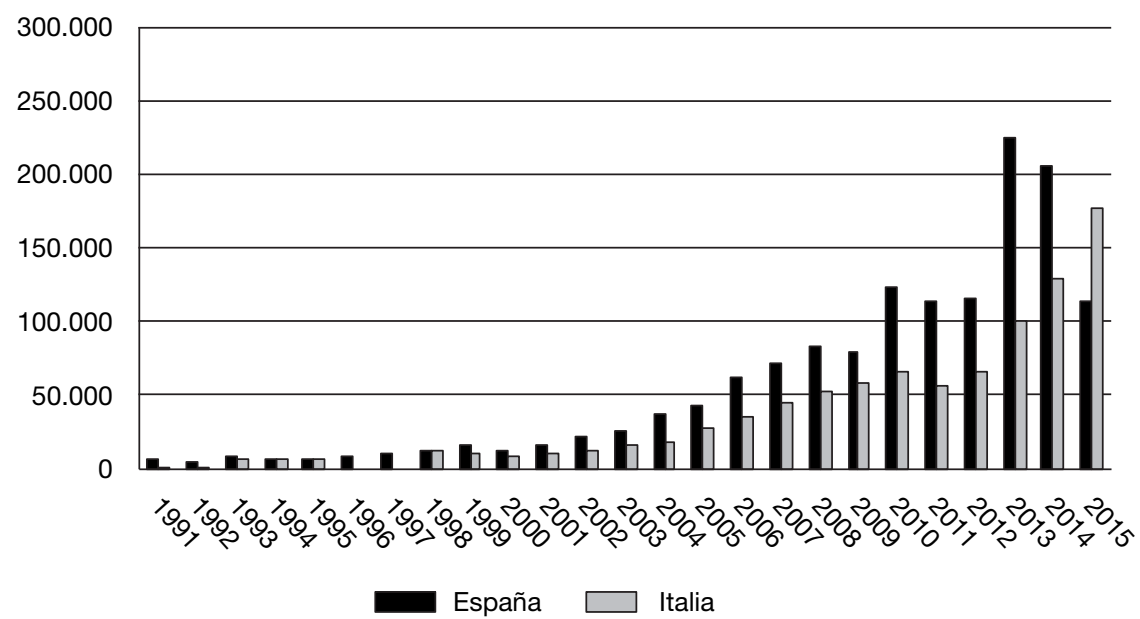

Fuente: elaboración propia a partir de los datos del Ministerio de Empleo y Seguridad Social, ISTAT (20022013) y Eurostat (para Italia antes de 2002).

nacionalidad española o italiana. En relación con el proceso de adquisición de la nacionalidad, es importante resaltar que la tasa de extranjeros naturalizados en España e Italia es menor que en muchos otros países europeos que cuentan con una experiencia migratoria más larga. Dichas diferencias se deben tanto a los flujos migratorios más recientes hacia España e Italia como al largo período de residencia legal previa impuesto en el proceso de naturalización en ambos países. Por regla general, la naturalización ordinaria requiere diez años de residencia legal y documentada en ambos países. En España, sin embargo, los latinoamericanos (y los nacionales de otros países con vínculos coloniales) se benefician de un acceso facilitado a la nacionalidad tras dos años de residencia legal.

Como muestra el gráfico 3, el número de extranjeros que han adquirido la nacionalidad española e italiana ha ido aumentando a lo largo del tiempo, particularmente tras la primera década del siglo XXI. Entre 1991 y 2015, cerca de 1.440.000 personas se han naturalizado en España, mientras que alrededor de 930.000 inmigrantes han adquirido la nacionalidad italiana.

Ninguno de estos dos países ofrece estadísticas fiables sobre el tamaño de las segundas generaciones, aunque la Encuesta Europea de Trabajo (EUELS, European Labour Survey) permite hacer algunas estimaciones al respecto. Conforme a los datos de la EU-ELS, en 2008, los inmigrantes de segunda generación representaban el 1,1 por ciento del total de la población de 25-54 años en España, con cerca de 200.400 personas descendientes de parejas mixtas (solo uno de los progenitores nacido en el extranjero) y 43.300 personas descendientes de parejas cuyos dos miembros habían nacido en el extranjero. La proporción es similar para Italia, con un 1 por ciento de inmigrantes de 
segunda generación entre la población de 25-54 años (237.800 personas descendientes de parejas mixtas y 16.500 personas descendientes de parejas con ambos progenitores nacidos en el extranjero) (Eurostat, 2011).

Pese a la magnitud impresionante del cambio social en España e Italia durante las últimas dos décadas, el fuerte vínculo entre nacionalidad y derecho de sufragio activo indica que gran parte de las POI residentes en ambos países no ha tenido derecho de voto en elecciones generales. Calcular el tamaño real del electorado inmigrante es una tarea difícil, aunque podemos hacer algunas estimaciones al sumar el número de inmigrantes residentes naturalizados hasta la fecha de cada elección en cada país ${ }^{2}$ y las estimaciones del número de adultos de segunda generación provenientes de los datos de EU-ELS ${ }^{3}$. En España, estos cálculos resultarían en una estimación de las POI con derecho a voto de menos de 250.000 personas para las elecciones de 1993, 1996 y 2000 (menos del 1 por ciento del electorado en cada convocatoria); 350.000 en 2004 (el 1 por ciento); 680.000 en 2008 (el 1,9 por ciento), 1.150.000 en 2011 (el 3,2 por ciento) y 2.160 .000 en 2015 (el 5,9 por ciento). Para Italia, estos cálculos resultarían en una estimación del electorado inmigrante de menos de 150.000 personas para las elecciones celebradas entre 1992 y 2001 (en torno al 0,3 por ciento del electorado), y de 330.000 y 500.000 personas, respectivamente, para las elecciones de 2006 y 2008 (casi el 1 por ciento del electorado). Sin embargo, lo más probable es que estas cifras subestimen el tamaño real del electorado inmigrante en ambos países, aunque permiten estimar al menos el número mínimo de POI con derecho a voto en las elecciones generales.

\subsection{Las actitudes de la población en torno a la inmigración en España e Italia}

Tal y como se ha señalado en la introducción, en un contexto de intensos flujos migratorios, los partidos tendrán que equilibrar la presión demográfica que conduciría a la inclusión de los nuevos grupos sociales en la escena política con las opiniones de la población autóctona que constituye el grueso de su electorado. ¿Cómo ha reaccionado el público ante este aumento sin precedentes de la población inmigrante en España e Italia? El gráfico 4 muestra, con datos de varias ediciones del Eurobarómetro, el porcentaje de encuestados en España

2. Los cálculos del número de inmigrantes residentes naturalizados se basan en el número acumulado de naturalizaciones desde 1980 para España (con datos del Ministerio de Empleo y Seguridad Social) y desde 1991 para Italia (con datos de ISTAT para el período 2002-2013 y de Eurostat para el período previo a 2002).

3. Dado que las cifras de segunda generación de la EU-ELS solo están disponibles para 2008, para los demás años electorales hemos estimado la segunda generación utilizando la siguiente fórmula: estimación segunda generación = número acumulado de naturalizaciones hasta cada año electoral / ratio entre naturalizaciones y segunda generación en 2008, donde la «ratio entre naturalizaciones y segunda generación en 2008» representa la ratio entre el número de personas naturalizadas hasta 2008 y el número de inmigrantes de segunda generación registrado en la encuesta EU-ELS para 2008 (dicha ratio ha sido proyectada linealmente para las fechas anteriores y posteriores a las de 2008 para obtener las estimaciones de la segunda generación en cada año electoral). 
Gráfico 4. Importancia atribuida a la inmigración en España e Italia (desde 2002)
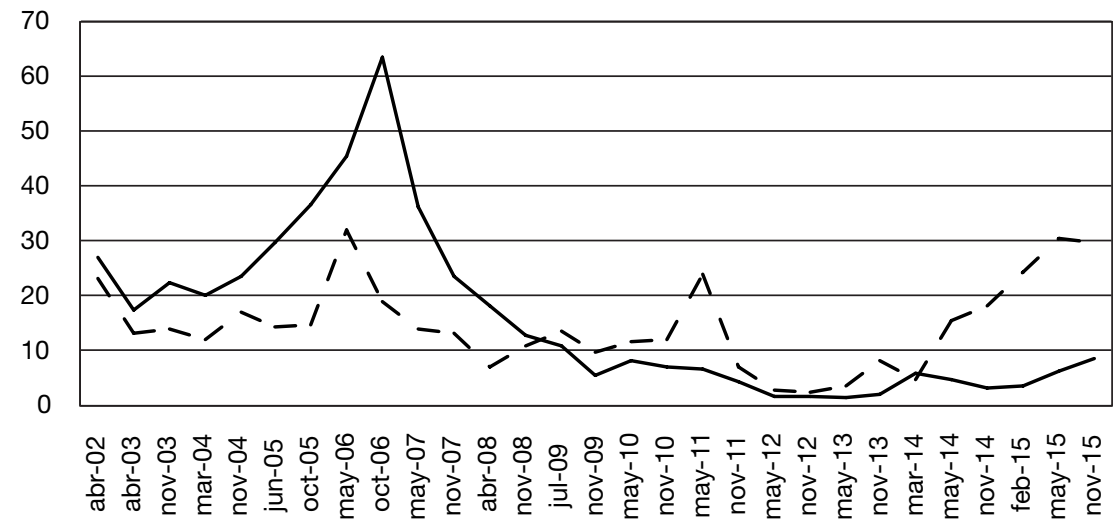

\section{España $\quad-\quad$ - Italia}

Fuente: elaboración propia a partir de los datos del Eurobarómetro: EB 57.2, EB 59.1, EB 60.1, EB 61, EB 62.0, EB 63.4, EB 64.2, EB 65.3, EB 66.1, EB 67.2, EB 68.1, EB 69.2, EB 70.1, EB 71.3, EB 72.4, EB 73.4, EB 74.2, EB 75.3, EB 76.3, EB 77.3, EB 78.1, EB 79.3, EB 80.1, EB 81.2, EB 81.4, EB 82.3, EB 83.1, EB 83.3, EB 84.3. Porcentaje de encuestados que considera la inmigración como uno de los dos problemas más importantes del país.

y en Italia que mencionan la inmigración como un problema importante en el país. Se observa que la relevancia (salience) de la inmigración como problema importante aumentó considerablemente en ambos países a lo largo de la primera mitad de la década del 2000.

Por lo general, los españoles se han mostrado más preocupados por la inmigración que los italianos hasta finales de la primera década del siglo XXI. En ambos países, la preocupación por la inmigración alcanzó un pico en 2006, cuando el 60 por ciento de los españoles y poco más del 30 por ciento de los italianos evaluaban la inmigración como uno de los principales problemas. Morales y Ros (2012) y Ros y Morales (2015) han argumentado que, en el caso español, dicho pico en la relevancia atribuida a la inmigración estaba relacionado con la crisis de la llegada de inmigrantes irregulares a las costas españolas ( «la crisis de los cayucos»).

Italia también experimentó en ese periodo un aumento considerable del número de llegadas de inmigrantes irregulares a las costas italianas, principalmente a Sicilia. Según las estimaciones, cerca de 13.500 personas en 2004 y 23.000 personas entre 2005 y 2006 llegaron a Italia a través de esta vía de acceso (Monzini, 2008). Sin embargo, después de 2006 se produjo un descenso significativo en la relevancia atribuida a la inmigración en ambos países, especialmente en España, donde desde 2009 solo el 10 por ciento de los encuestados mencionaba la inmigración como uno de los dos problemas más importantes del país. En Italia, la preocupación por la inmigración ha vuelto a aumentar durante 
los últimos años y, en 2015, cerca del 30 por ciento de italianos consideraba la inmigración como un problema, un porcentaje tres veces superior al de españoles que consideraban la inmigración un problema importante en esa misma fecha.

Los gráficos 5 y 6 muestran los resultados de varias encuestas internacionales acerca de la evolución de la opinión pública en España e Italia sobre

Gráfico 5. Actitudes hacia la inmigración y los inmigrantes en España e Italia (desde 1990)

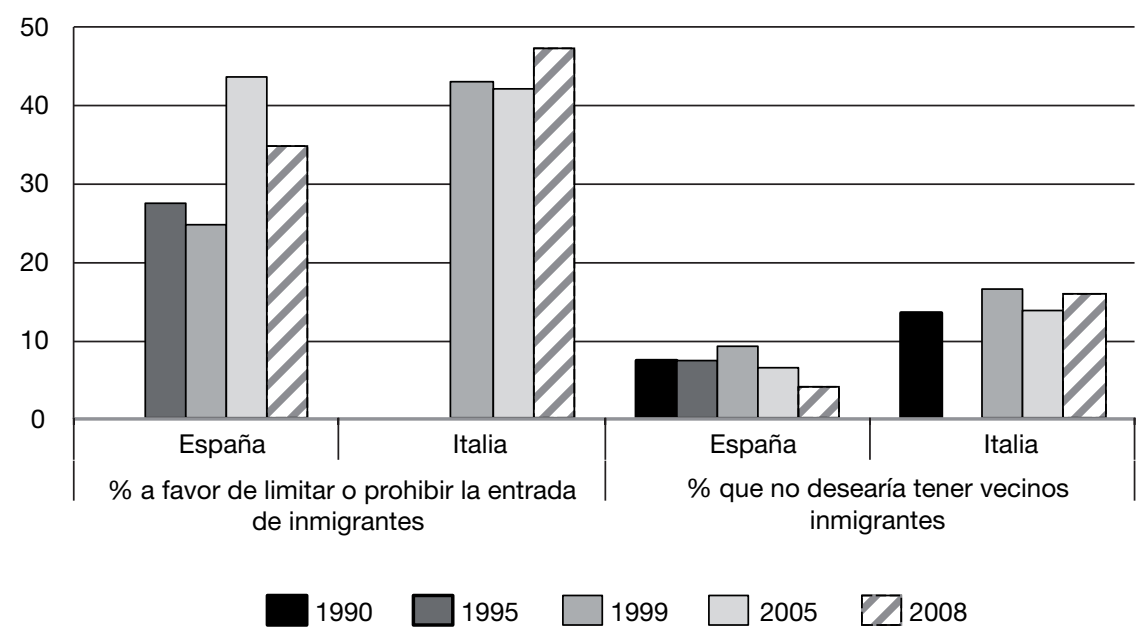

Fuente: elaboración propia a partir de los datos de la Encuesta Europea de Valores (1990, 1999 y 2008) y de la Encuesta Mundial de Valores (1995 y 2005).

Gráfico 6. Actitudes hacia el efecto de la inmigración sobre la economía nacional (desde 2002)

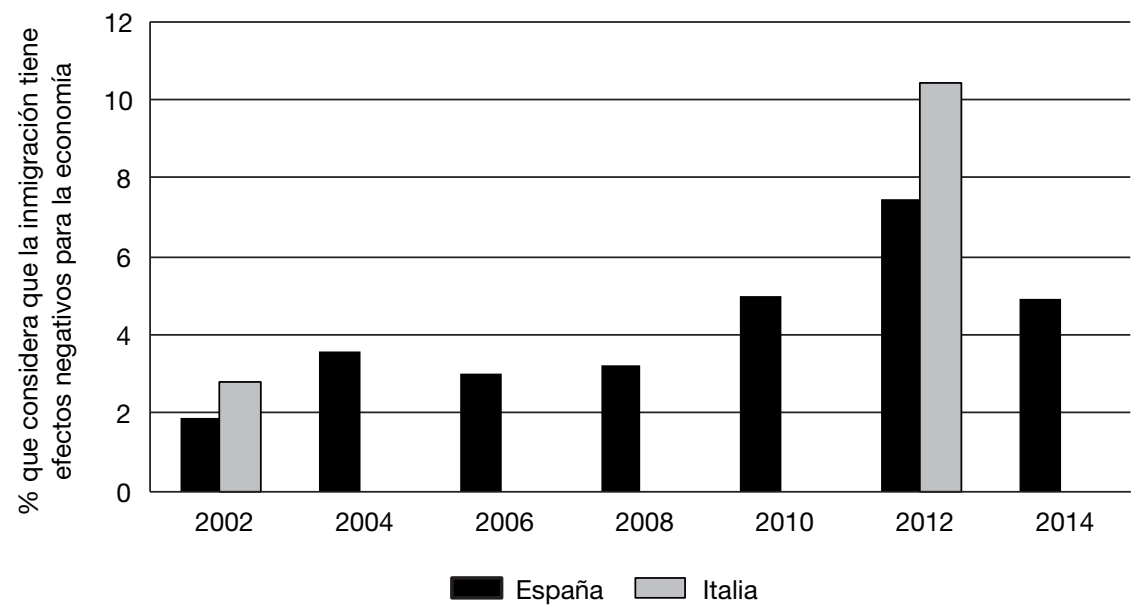

Fuente: elaboración propia a partir de los datos de la Encuesta Social Europea (varias ediciones). 
Gráfico 7. Actitudes hacia el reconocimiento del derecho de voto a los extranjeros en España e Italia (desde 1993)

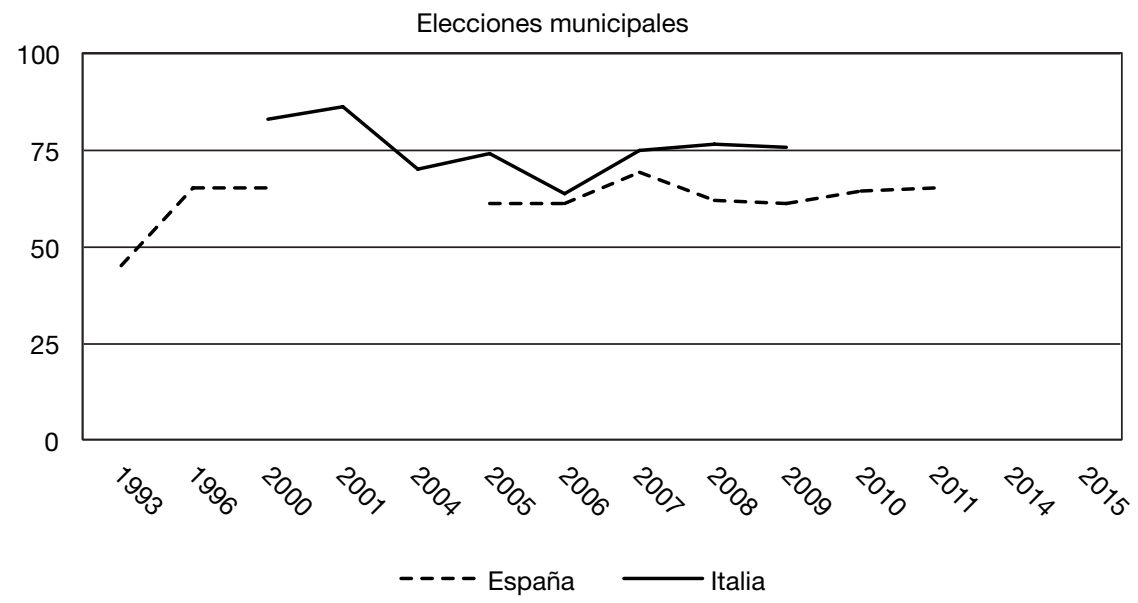

Elecciones generales

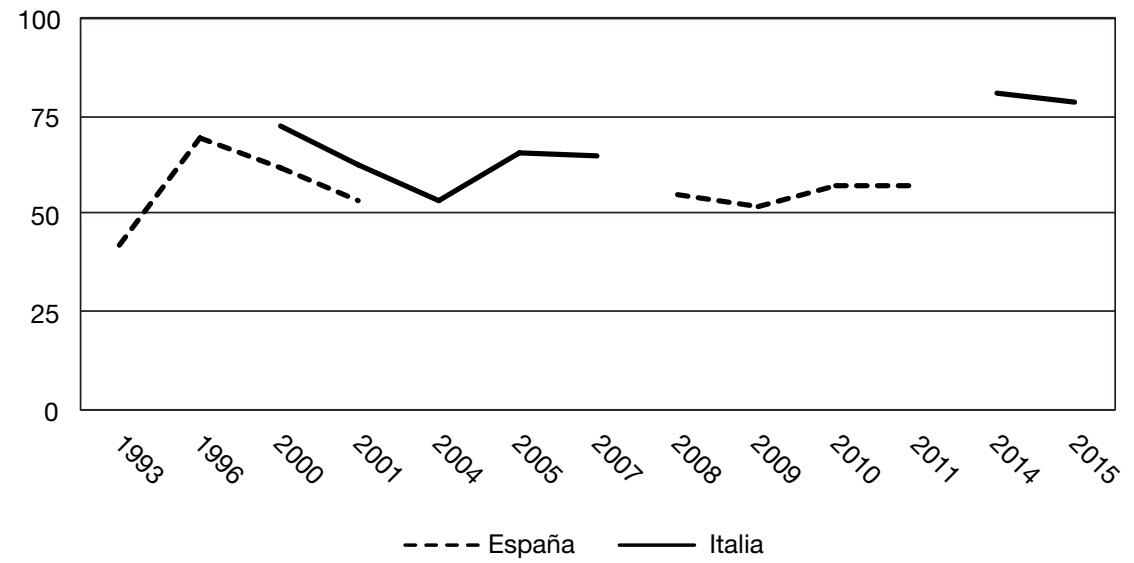

Fuente: elaboración propia a partir de los datos del CIS (encuestas $n .^{\circ} 2383,2625,2731$ y 2773 ) y los datos de la Fondazione Nord-Est (2000-2005) y la Fondazione Demos \& Pi (2006-2008). Porcentaje a favor del reconocimiento del derecho de voto a los extranjeros en elecciones municipales y generales.

algunos aspectos específicos relacionados con la inmigración, tales como las actitudes hacia la entrada de extranjeros, las percepciones hacia los inmigrantes como vecinos y el impacto de la inmigración sobre la economía nacional. Los datos muestran que las percepciones hacia la inmigración varían considerablemente entre los dos países, dependiendo de la dimensión evaluada en cada caso. Por lo general, tanto los españoles como los italianos parecen mostrar actitudes más hostiles hacia la llegada de extranjeros que hacia los inmigrantes 
como tales. Al menos uno de cada cuatro españoles e italianos han apoyado la idea de restringir la inmigración. Estas actitudes restrictivas parecen mucho más prevalentes entre los italianos que entre los españoles, aunque en ambos países el apoyo a políticas migratorias restrictivas ha ido aumentando a lo largo del tiempo.

Sin embargo, otros aspectos sociales o económicos relacionados con la inmigración parecen desencadenar actitudes menos hostiles; por ejemplo: los porcentajes de encuestados que rechazan la idea de tener inmigrantes como vecinos y de quienes consideran que la inmigración puede provocar efectos económicos negativos (gráfico 6) han sido sustancialmente más bajos en ambos países. Aun así, la hostilidad hacia los inmigrantes parece ser más pronunciada en Italia que en España, y las percepciones acerca del impacto negativo de la inmigración sobre la economía nacional han ido aumentado en ambos casos.

Finalmente, el gráfico 7 muestra la evolución de la opinión pública hacia el reconocimiento del derecho de voto a los extranjeros en elecciones municipales y generales en España e Italia, empleando datos de encuestas de ámbito nacional en ambos países. Durante la mayor parte del periodo considerado, una mayoría de españoles y de italianos han apoyado la idea de extender el derecho de voto a los extranjeros, ya sea a nivel local o en las elecciones generales. En ambos países, dicho apoyo es mayor cuando se trata de elecciones municipales. Es más, a diferencia de las pautas previamente señaladas sobre actitudes negativas hacia la inmigración, las actitudes positivas respecto a los derechos electorales de los extranjeros han sido constantemente más altas en Italia que en España, y dichas tendencias en la opinión pública se han mantenido más o menos estables a lo largo del período analizado en ambos casos.

\subsection{El papel de los partidos como guardianes del sistema politico: Oportunidades y obstáculos para la representación política de los inmigrantes en España e Italia}

Tal como se ha mencionado previamente, cuando el público no se muestra particularmente entusiasta sobre la inmigración o la integración de los inmigrantes, la decisión de los partidos de incluir POI en sus listas electorales puede verse condicionada por los costes electorales anticipados. ¿Cómo han reaccionado los partidos en España y en Italia ante el aumento del fenómeno migratorio? Para empezar, es importante destacar que el apoyo electoral hacia partidos antiinmigración varía sustancialmente entre estos dos países.

En España no existe ningún partido de ámbito nacional que apoye de manera inequívoca políticas antiinmigración. Aunque el Partido Popular (PP) ha mostrado una posición más restrictiva al respecto, aún está lejos de ser un partido antiinmigración, puesto que su discurso a nivel nacional sobre este tema sigue siendo bastante moderado (Morales et al., 2014). Por otra parte, el sistema electoral español impone barreras de entrada muy altas, por lo que los partidos más pequeños de extrema derecha afrontan grandes dificultades para 
obtener escaños en el Congreso. De hecho, el apoyo electoral hacia partidos antiinmigración o de extrema derecha a nivel nacional ha sido muy reducido, apenas el 0,2 por ciento del total de los votos en las elecciones generales celebradas entre 1993 y $2015^{4}$. Sin embargo, sí existen algunos partidos más pequeños de ámbito local, sobre todo en Cataluña, que tienen un discurso muy radical en contra de la inmigración y que han obtenido un cierto éxito electoral en elecciones municipales (véase el ejemplo de Plataforma per Catalunya, $\mathrm{PxC}$ ).

La situación es muy distinta en Italia, donde varios partidos de extrema derecha o con un fuerte discurso en contra de los inmigrantes han conseguido escaños en el Parlamento durante el período analizado. El discurso antiinmigración se puede encontrar, por ejemplo, en los programas de partidos políticos como La Derecha (La Destra) o la Liga Norte (Lega Nord, LN). Mientras que La Derecha no consiguió ningún escaño en el Parlamento italiano hasta 2008, la Liga Norte obtuvo porcentajes considerables de apoyo durante el periodo estudiado: un 8,7 en 1992, un 8,4 en 1994, un 10,1 en 1996, un 3,9 en 2001, un 4,6 en 2006 y un 8,3 en 2008. Para el período analizado, también es importante destacar el éxito electoral del Movimiento Social Italiano-Derecha Nacional (Movimento Sociale Italiano-Destra Nazionale, MSI-DN), con un 5,3 por ciento de los votos en 1991, y Alianza Nacional (Alleanza Nazionale, AN), con un 13,5 por ciento en 1994 y un 15,7 en 1996.

El gráfico 8 compara la diversidad y la polarización de las posiciones de los partidos españoles e italianos en torno a la inmigración a partir de datos de las encuestas a expertos de Chapel Hill (Bakker et al., 2012). Se muestra la distribución de las posiciones medias de los partidos con respecto a cuán restrictiva debería ser la política migratoria, en una escala de cero a diez. Las posiciones más cercanas a cero representan una fuerte oposición hacia políticas migratorias restrictivas y las posiciones más cercanas a diez representan un fuerte apoyo a políticas restrictivas en materia de inmigración.

A la luz de los datos mostrados, la posición de los partidos españoles e italianos en torno a la inmigración está fuertemente relacionada con la dimensión izquierda-derecha, y en ambos países la polarización de estas posiciones ha ido aumentando con el tiempo, particularmente en Italia. El gráfico 8 también muestra que el espacio antiinmigración está mucho mejor representado en Italia que en España, lo que nos hace esperar que la inclusión de candidatos y candidatas inmigrantes sea más costosa ideológicamente para los principales partidos de centroderecha en Italia (FN, AN, LN) que para el PP en España. Del mismo modo, los principales partidos del centroizquierda en Italia (DS inicialmente, $\mathrm{PD}$ posteriormente) han ocupado posiciones más nítidamente antirrestrictivas que las de su homólogo en España (PSOE) y, por tanto, cabe esperar que los partidos italianos de centroizquierda adopten una posición más

4. Esto incluye a Falange Española de las JONS, La Falange, Democracia Nacional, Alternativa Española, ESPAÑA 2000, Falange Auténtica y Movimiento Falangista de España. 
Gráfico 8. Las posiciones de los partidos españoles e italianos sobre la política migratoria

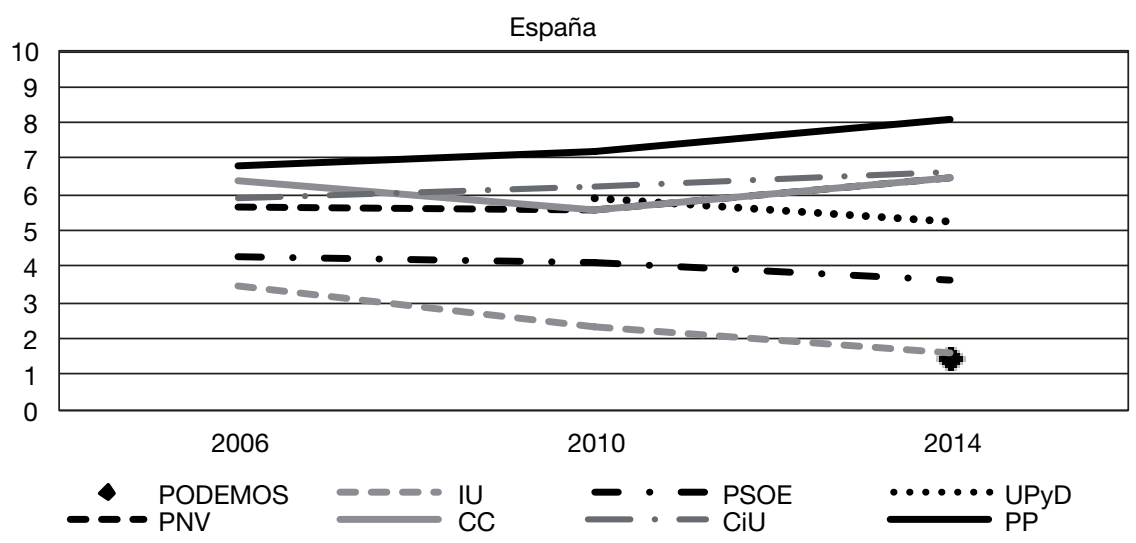

Italia

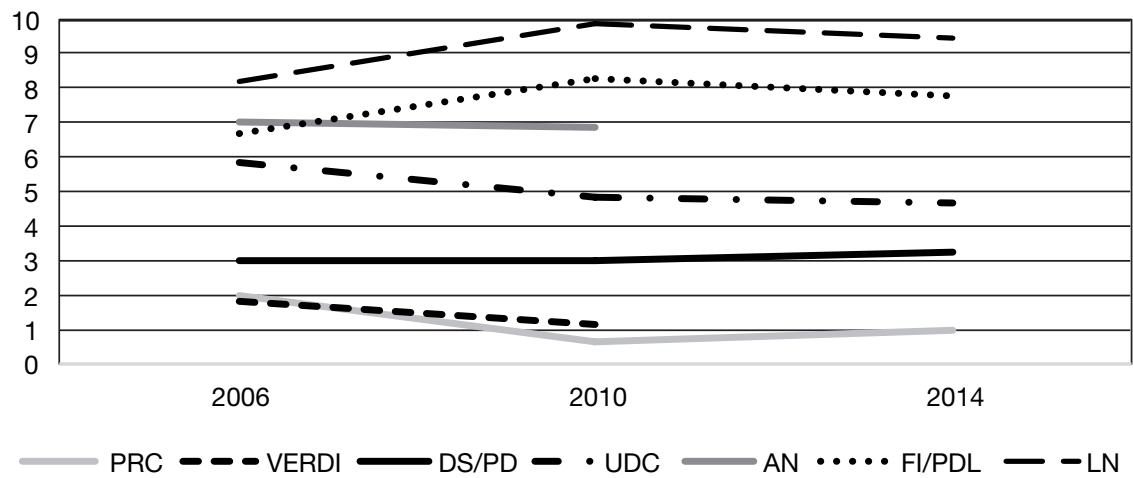

Fuente: Chapel Hill Expert Surveys, 2006, 2010, 2014. Acrónimos usados para los partidos en España: CC (Coalición Canaria), CiU (Convergència i Unió), IU (Izquierda Unida), PNV (Partido Nacionalista Vasco), PP (Partido Popular), PSOE (Partido Socialista Obrero Español), Podemos, UPyD (Unión, Progreso y Democracia). Acrónimos usados para los partidos en Italia: AN (Alleanza Nazionale), DS (Democratici di Sinistra), FI (Forza Italia), PDL (II Popolo della Libertà), LN (Lega Nord), PD (Partito Democratico), PRC (Partito della Rifondazione Comunista), UDC (Unione di Centro), VERDI (Federazione dei Verdi).

decisiva hacia la nominación de candidatos y candidatas inmigrantes que los partidos españoles situados en el mismo espectro ideológico.

Junto con la presencia y el éxito electoral de los partidos antiinmigración, otros aspectos relacionados con el sistema electoral o la organización interna de los partidos españoles e italianos también podrían influir en su propensión a incluir candidatos y candidatas de origen inmigrante (Caul, 1999; Norris, 2006; Claro da Fonseca, 2011). En relación con el sistema electoral, conviene resaltar el potencial efecto de la magnitud del distrito electoral sobre la nominación de candidatos y candidatas inmigrantes. Tanto en España (durante todo 
el período analizado) como en Italia (solo desde 1993 hasta 20055), la magnitud del distrito ha sido relativamente baja ${ }^{6}$. Por lo tanto, el número medio de candidatos y candidatas en posiciones «seguras» por partido en algunas circunscripciones electorales ha sido reducido, algo que ha podido dificultar la inclusión de las POI en las listas electorales.

Adicionalmente, la nominación de candidatos y candidatas inmigrantes también depende del grado de apertura de los partidos hacia la inclusión de las POI en sus estructuras internas. Pese a que algunos partidos españoles e italianos han implementado cuotas para la inclusión de mujeres, ninguno de ellos ha institucionalizado cuotas similares para las POI y muy pocos han creado agrupaciones internas orientadas específicamente hacia la población inmigrante. En Italia, los partidos que han conseguido representación parlamentaria desde la década de 1990 no han mostrado ningún interés particular en diseñar mecanismos específicos para la inclusión de las POI en sus estructuras. El principal partido de centroizquierda italiano (PD) se marcó como objetivo crear una agrupación para los inmigrantes en la primera década del siglo XXI (Cappiali, 2015), aunque sin éxito. En España, IU e Iniciativa per Catalunya Verds (ICV) formaron grupos de trabajo sobre la inmigración en los que participaban tanto las POI como la población autóctona. En el ámbito nacional español, solo el PSOE ha creado una agrupación interna para sus miembros de origen africano (en 2005), así como agrupaciones similares para los afiliados socialistas de origen latinoamericano y árabe (en 2006) ${ }^{7}$.

Dada esta estructura de demandas demográficas y de potenciales costes para la representación política de las POI en España y en Italia, en este artículo desarrollamos varias hipótesis, tal como se ha destacado en la introducción. Primero, dada la intensificación de los flujos migratorios durante la primera década del siglo XXI y el largo período de residencia previa requerido para acceder a la nacionalidad y para poder presentarse como candidatos en elecciones generales en España y en Italia, cabe esperar que los partidos españoles e italianos hayan incorporado de forma progresiva algunos diputados y diputadas de origen inmigrante, aunque más bien de manera simbólica como gesto de adaptación a los cambios demográficos. Por tanto, esperamos encontrar niveles muy bajos de representación política de las POI en ambos países, con porcentajes de diputados y diputadas de origen inmigrante por debajo del tamaño relativo de este colectivo en el conjunto poblacional.

5. El sistema electoral italiano ha cambiado varias veces desde principios de los años noventa, desde un sistema casi puramente proporcional para las elecciones de 1992 hasta un sistema mixto tras la introducción de la Ley Mattarella en 1993, y un sistema de representación proporcional con bonificación ajustada tras la reforma electoral de 2005.

6. La magnitud media del distrito ha sido de 7 en España durante el período analizado. En Italia, la magnitud media ha sido de 19 para las elecciones de 1992; 2 para las elecciones celebradas entre 1994 y 2001, y 23 para las elecciones de 2006 y 2008.

7. Véase http://www.psoe.es/ambito/afrosocialista/news/index.do, http://www.psoe.es/ambito/ latino/news/index.do y http://www.psoe.es/ambito/arabessocialistas/news/index.do. 
Segundo, teniendo en cuenta la mayor intensidad de los flujos migratorios hacia España, el hecho de que gran parte de ellos esté compuesta por latinoamericanos — que se benefician de un acceso facilitado a la nacionalidad-, que la opinión pública española haya mostrado actitudes más favorables hacia la inmigración y que no haya un verdadero partido antiinmigración, cabe esperar que el nivel de representación política de las POI sea algo mayor en España que en Italia. Tercero, a la vista del aumento de las actitudes negativas hacia la inmigración en ambos países, partimos de la hipótesis de que los partidos serán más proclives a incluir candidatos y candidatas «invisibles» en vez de minorías «visibles» en sus listas, a fin de disminuir el riesgo de suscitar reacciones negativas entre el electorado. De este modo, otra de nuestras hipótesis es que las POI procedentes de la UE y la comunidad albanesa conseguirán mayor representación en el Parlamento italiano que otros colectivos de origen inmigrante, mientras que los latinoamericanos y los inmigrantes comunitarios deberían obtener más escaños en el Congreso de los Diputados en España que el resto de colectivos de origen inmigrante. Por último, dados los pocos incentivos electorales que tienen los partidos para nominar candidatos y candidatas de origen inmigrante, esperamos que en ambos países — pero particularmente en Italia — dichas nominaciones simbólicas sean más frecuentes entre los partidos de centroizquierda que entre los de centroderecha.

\section{Datos y fuentes}

El presente estudio utiliza una base de datos original recopilada en el marco del proyecto internacional Pathways to power, que analiza la representación política de las POI en Alemania, Bélgica, Francia, España, Grecia, Holanda, Italia y Reino Unido (Morales et al. 2017). La base de datos recoge información acerca del perfil sociodemográfico y político de todos los diputados y diputadas electos para el Congreso de los Diputados desde 1993 hasta 2016 (legislaturas V a XI) y para la Camera dei Deputati en Italia desde 1993 hasta 2013 (legislaturas XI a XVI).

El análisis incluye a todos los diputados y diputadas electos desde comienzos de cada legislatura, así como quienes entraron en el Parlamento como personas sustitutas. De este modo, la base de datos contiene información sobre 2.832 diputados y diputadas para España y 3.898 diputados y diputadas para Italia ${ }^{8}$. Respecto a cada individuo, se ha recopilado información sobre el perfil sociodemográfico (edad, género, educación, ocupación, país de nacionalidad y país de nacimiento del diputado o de la diputada y de sus progenitores); los roles parlamentarios (experiencia parlamentaria, afiliación

8. A diferencia del Congreso español, que tiene 350 escaños, el tamaño de la Cámara Baja del Parlamento italiano es de 630 diputados. Para las legislaturas italianas que han empezado en 2006 y 2008, nuestro análisis excluye a los diputados y diputadas electos en la circunscripción electoral de residentes en el extranjero (Circoscrizione Estero, con 12 escaños asignados para cada legislatura). 
partidista, posición en las listas electorales, pertenencia a grupos y comisiones parlamentarias, así como funciones asumidas en el Parlamento durante cada legislatura), y la carrera política (posición en el partido, afiliaciones partidistas previas, cargos electos previos a nivel local, regional, nacional y europeo, cargos gubernamentales, etc.).

En todos los casos, dicha información ha sido recogida a través de fuentes públicas. Primero, se ha utilizado la información proporcionada en las páginas web de los parlamentos de cada país. En una segunda etapa, dichos datos han sido complementados con fuentes adicionales, tales como las páginas web de los partidos políticos, las redes sociales de los diputados y diputadas, Wikipedia, periódicos nacionales, regionales o locales, etc. $\mathrm{Al}$ igual que otros estudios previos (Bird, 2005; Bird et al., 2011; Bloemraad, 2013), nuestro artículo utiliza una definición del origen inmigrante de los representantes y de las representantes electos basada en su lugar de nacimiento y su nacionalidad al nacer, así como el lugar de nacimiento y la nacionalidad de los padres al nacer. Por tanto, nuestra definición de diputados y diputadas de origen inmigrante cubre todos los colectivos de origen extranjero y, a diferencia de la mayoría de los estudios previos sobre este tema, no se limita a estudiar solo a las minorías más «visibles» o no occidentales. Siguiendo esta definición, identificamos como diputado o diputada de origen inmigrante a quienes:

a) Hayan nacido en el extranjero de nacionalidad no española o no italiana (inmigrantes de primera generación) o;

b) Hayan tenido al menos un progenitor de nacionalidad extranjera al nacer (inmigrantes de segunda generación).

Nuestro estudio no considera POI a quienes han nacido en el extranjero pero no tienen origen inmigrante, como es el caso de los descendientes de emigrantes o quienes han nacido en las antiguas colonias o dominios de los países analizados cuando aún formaban parte del territorio nacional.

La información sobre el perfil sociodemográfico, la carrera política, los roles parlamentarios y el lugar de nacimiento de los diputados y diputadas se ha podido encontrar fácilmente a través de las fuentes públicas previamente mencionadas. Sin embargo, encontrar información sobre el origen de los progenitores de los diputados y de las diputadas ha sido una tarea más difícil. Asimismo, se han encontrado datos fiables sobre el origen de al menos uno de los progenitores para cerca de un tercio de los diputados y de las diputadas analizados para cada legislatura en España e Italia. En aquellos casos en los cuales no se dispone de ninguna información en el dominio público acerca del lugar de nacimiento o de la nacionalidad de los padres, se ha asumido que el diputado o la diputada no tiene origen inmigrante, sobre todo si ninguna de las informaciones adicionales recopiladas sobre él o ella indicaba lo contrario. Por ese motivo, las cifras totales de diputados y diputadas que no tienen origen inmigrante deben interpretarse con cierta cautela. 


\section{La representación descriptiva de los inmigrantes en España e Italia}

\subsection{Comparación de los niveles de representación politica real y perfecta}

La tabla 1 presenta algunos resultados sobre los niveles de representación descriptiva de las POI en España e Italia. Para empezar, los datos muestran que más del 1 por ciento de los diputados y diputadas de cada legislatura analizada en cada país han nacido en el extranjero. Sin embargo, en ambos casos, estos porcentajes son considerablemente inferiores a las tasas de población nacida fuera del país, con una brecha más grande en España, sobre todo a partir de 2004. De todos modos, haber nacido fuera del país no significa necesariamente que estas personas sean de origen inmigrante, ya que podrían ser descendientes de emigrantes. Volviendo a nuestra definición de las POI, observamos que solo el 1 por ciento o menos de los diputados y de las diputadas en España son de origen inmigrante. En Italia encontramos proporciones similares, aunque ligeramente más altas para las dos últimas legislaturas (casi un 2 por ciento).

Partiendo de estas cifras, ¿̇ómo podríamos evaluar los niveles de representación política de las POI en España e Italia? Establecer los límites del demos de origen inmigrante que puede legítimamente aspirar a ser representado de forma descriptiva no es una tarea fácil. Una opción minimalista sería simplemente calcular el tamaño aproximado del electorado inmigrante (ver los cómputos correspondientes en la sección 2.1.), lo que devolvería cifras reducidas de entre el 1 y el 6 por ciento de POI en ambos países a lo largo de todo el periodo. Estos porcentajes son bastante similares a los niveles reales de representación política que las POI han obtenido en España e Italia al comienzo del periodo, pero marcan una diferencia notable entre población representada y población representante para las últimas legislaturas consideradas. Sin embargo, estas estimaciones son bastante conservadoras, ya que se basan en una definición restrictiva del demos conforme a la cual solo quienes disfrutan de plenos derechos de ciudadanía podrían aspirar a ver sus intereses representados en la política nacional.

Una segunda forma más inclusiva de medir la representación perfecta supone considerar que el demos resulta de la suma del número de extranjeros residentes en cada año electoral y el número de inmigrantes residentes naturalizados hasta dicho año. Si duplicamos estas cifras para incluir también a las segundas generaciones, nuestros cálculos apuntarían a que las POI representaban entre el 1 y el 7 por ciento del total poblacional en Italia y entre 1 y el 15 por ciento en España a lo largo del periodo considerado. Si tomamos en consideración esta estimación más inclusiva, nuestros resultados apuntan hacia una pauta clara de infrarrepresentación de las POI en los parlamentos nacionales de ambos países, con porcentajes de diputados y diputadas de origen inmigrante que están muy por debajo de las cifras esperadas en función de su peso demográfico en el conjunto de la población.

Los resultados de nuestro estudio indican que dichas pautas de infrarrepresentación también se mantienen cuando analizamos la presencia de las POI en parlamentos autonómicos. Para ello, hemos seleccionado una mues- 
Tabla 1. Diputados y diputadas por país de nacimiento y origen inmigrante (OI) comparado con la población, por legislatura

\begin{tabular}{|c|c|c|c|c|c|c|c|c|c|c|c|c|c|}
\hline \multirow[b]{2}{*}{ Legislaturas } & \multicolumn{7}{|c|}{ España } & \multicolumn{6}{|c|}{ Italia } \\
\hline & $\begin{array}{l}1993- \\
1996\end{array}$ & $\begin{array}{l}1996- \\
2000\end{array}$ & $\begin{array}{l}2000- \\
2004\end{array}$ & $\begin{array}{l}2004- \\
2008\end{array}$ & $\begin{array}{c}2008- \\
2011\end{array}$ & $\begin{array}{l}2011- \\
2015\end{array}$ & $\begin{array}{l}2016- \\
2016\end{array}$ & $\begin{array}{l}1992- \\
1994\end{array}$ & $\begin{array}{l}1994- \\
1996\end{array}$ & $\begin{array}{l}1996- \\
2000\end{array}$ & $\begin{array}{l}2001- \\
2006\end{array}$ & $\begin{array}{c}2006- \\
2008\end{array}$ & $\begin{array}{l}2008- \\
2013\end{array}$ \\
\hline $\mathrm{N}$ total de diputados y diputadas & 407 & 409 & 416 & 399 & 413 & 437 & 351 & 653 & 639 & 652 & 645 & 638 & 671 \\
\hline $\begin{array}{l}\text { Porcentaje de diputados y diputa- } \\
\text { das nacidos en el extranjero }\end{array}$ & 1,7 & 2,0 & 2,4 & 2,5 & 1,9 & 1,2 & 2,4 & 1,4 & 1,7 & 1,8 & 1,7 & 2,0 & 1,6 \\
\hline $\begin{array}{l}\text { Porcentaje de población nacida } \\
\text { en el extranjero }{ }^{+}\end{array}$ & 1,1 & 2,7 & 3,6 & 8,7 & 13,2 & 14,3 & 13,2 & 1,1 & 1,1 & 1,3 & 2,4 & 4,6 & 9,9 \\
\hline $\begin{array}{l}\text { Ratio entre porcentaje de dipu- } \\
\text { tados y porcentaje de población } \\
\text { nacida en el extranjero }\end{array}$ & 1,5 & 0,7 & 0,7 & 0,3 & 0,1 & 0,1 & 0,2 & 1,3 & 1,5 & 1,4 & 0,7 & 0,4 & 0,2 \\
\hline $\begin{array}{l}\text { Porcentaje de diputados y diputa- } \\
\text { das de origen inmigrante }\end{array}$ & 0,7 & 0,7 & 1,0 & 1,0 & 1,0 & 0,7 & 1,1 & 0,9 & 0,6 & 0,6 & 0,9 & 1,6 & 1,5 \\
\hline $\begin{array}{l}\text { Porcentaje de electorado 이 } \\
\text { (estimación minimalista) }\end{array}$ & 0,4 & 0,5 & 0,7 & 1,0 & 1,9 & 3,2 & 5,9 & 0,0 & 0,0 & 0,1 & 0,3 & 0,7 & 1,0 \\
\hline $\begin{array}{l}\text { Ratio entre porcentaje de diputa- } \\
\text { dos y porcentaje de electorado 0I } \\
\text { (minimalista) }\end{array}$ & 1,8 & 1,4 & 1,4 & 1,0 & 0,5 & 0,2 & 0,2 & - & - & 6,0 & 3,0 & 2,6 & 1,6 \\
\hline $\begin{array}{l}\text { Porcentaje de población 0I } \\
\text { (estimación maximalista) }^{\star \star}\end{array}$ & 1,3 & 1,7 & 2,7 & 8,0 & 13,0 & 14,5 & 13,7 & 1,2 & 1,2 & 1,4 & 2,7 & 5,2 & 6,7 \\
\hline $\begin{array}{l}\text { Ratio entre porcentaje de diputa- } \\
\text { dos y porcentaje de población 0I } \\
\text { (maximalista) }\end{array}$ & 0,5 & 0,4 & 0,4 & 0,1 & 0,1 & 0,0 & 0,1 & 0,8 & 0,5 & 0,4 & 0,3 & 0,3 & 0,2 \\
\hline
\end{tabular}

Fuente: elaboración propia a partir de los datos de Pathways.

+ Los cálculos acerca del porcentaje de población nacida en el extranjero del total de la población residente en cada año electoral proceden de INE, ISTAT y Eurostat. Dicho porcentaje se refiere a residentes nacidos en el extranjero para todas las fechas electorales analizadas, excepto para España 1993 e Italia 1992-2006 para los que se han utilizado datos referentes a extranjeros, en vez de nacidos en el extranjero. Para Italia 2008, el cálculo de la población nacida en el extranjero es una estimación basada en los datos de Eurostat de 2009 sobre el número de residentes nacidos en el extranjero.

* La estimación minimalista incluye solo las estimaciones acerca del tamaño del electorado inmigrante para cada año electoral descritas en la sección 2.1.

** La estimación maximalista incluye los datos de extranjeros residentes, del número de inmigrantes residentes naturalizados y las estimaciones del tamaño de las segundas generaciones para cada año electoral descritas en la sección 2.1 .

tra aleatoria estratificada por porcentaje de población extranjera de regiones en ambos países: Islas Baleares, Castilla-La Mancha, Galicia y Navarra, en España, y Abruzos, Marcas, Cerdeña y Umbría, en Italia. Para cada región, hemos seleccionado solo el último período legislativo ya finalizado, es decir, la legislatura 2011-2015 para las Islas Baleares, Castilla-La Mancha y Navarra, la legislatura 2012-2015 para Galicia, la legislatura 2009-2014 para Abruzos y Cerdeña y la legislatura 2010-2015 para Marcas y Umbría. La proporción de inmigrantes sobre el total poblacional de estas regiones en cada año electoral analizado varía notablemente. En España, dicha proporción es más baja en Galicia (un 7,5 por ciento de POI en el total de la población), pero bastante 
más alta en las restantes regiones: un 11,6 por ciento en Castilla-La Mancha, un 14 por ciento en Navarra y un 24,3 por ciento en las Islas Baleares. En Italia, el porcentaje de extranjeros sobre el conjunto poblacional varía entre el 1,8 por ciento en Cerdeña, el 4,5 por ciento en Abruzos, el 8,9 por ciento en Marcas y el 10,4 por ciento en Umbría.

Nuestro análisis de los diputados y de las diputadas autonómicos muestra que, pese a la elevada concentración demográfica de las POI en las cuatro regiones incluidas en la muestra española, este colectivo no ha logrado asegurar su presencia en ninguno de los parlamentos autonómicos analizados. En cada caso, pero especialmente en Galicia, hemos identificado algunos diputados y diputadas autonómicos nacidos fuera del país, pero ninguno de ellos es de origen inmigrante.

Las regiones italianas comparten la misma pauta de infrarrepresentación de las POI, ya que Cerdeña es la única región de la muestra italiana en la que se observa una presencia limitada de representantes de origen inmigrante en el Parlamento autonómico (solo el 1 por ciento del total de diputados y diputadas). Por lo tanto, en ambos países la población inmigrante parece enfrentarse a barreras aún más importantes para acceder a los parlamentos autonómicos que para entrar en el Parlamento nacional, ya que la pauta de escasa representación de las POI en estas regiones es aún más destacable que a nivel nacional. No encontramos, pues, ninguna evidencia empírica que permita afirmar que el nivel subnacional de gobierno es más permeable o más cercano a la realidad sociodemográfica que el nivel nacional.

\section{2. ¿Quiénes son los diputados y las diputadas de origen inmigrante? ¿Cómo llegan al Parlamento nacional?}

Volviendo a los representantes y a las representantes electos a nivel nacional, la tabla 2 muestra los resultados de análisis estadísticos bivariados acerca de la distribución de los diputados y de las diputadas nacionales en España e Italia por origen inmigrante, características sociodemográficas y trayectorias políticas.

Comenzando con el perfil sociodemográfico, los datos indican que, al igual que los diputados y las diputadas que no tienen origen inmigrante, la mayoría de los representantes inmigrantes en España e Italia son hombres de mediana edad. En España, casi todos cuentan con niveles educativos altos. En Italia, el porcentaje de diputados y diputadas de origen inmigrante que tienen credenciales educativas universitarias es sustancialmente menor (un 48 por ciento) que en España, e incluso menor que para los diputados y diputadas que no tienen origen inmigrante. Por otra parte, los datos apoyan nuestra hipótesis mostrando que la mayoría de estos representantes inmigrantes pertenecen a minorías «invisibles», y solo en Italia hemos identificado un porcentaje más alto de diputados y diputadas cuyo origen extranjero podría ser fácilmente identificable por los votantes.

En ambos países, más de un tercio de los diputados y diputadas de origen inmigrante nacieron en el extranjero. El 40 por ciento en España y el 65 por 
Tabla 2. Diputados y diputadas en España e Italia por origen inmigrante, características sociodemográficas, roles y experiencia en el Parlamento (todas las legislaturas)

\begin{tabular}{|c|c|c|c|c|}
\hline \multirow[b]{2}{*}{ Origen inmigrante } & \multicolumn{2}{|c|}{ España } & \multicolumn{2}{|c|}{ Italia } \\
\hline & Sin Ol & Con OI & Sin OI & Con OI \\
\hline Total de diputados y diputadas & 2.807 & 25 & 3.858 & 40 \\
\hline Porcentaje de nacidos en el extranjero & 1,7 & $36,0^{\star \star \star}$ & 1,4 & $35,0^{* * *}$ \\
\hline Porcentaje de minorías visibles & 0,1 & $4,5^{\star \star \star}$ & 0,6 & $26,5^{\star \star *}$ \\
\hline Porcentaje de descendientes de parejas mixtas & - & 40,0 & - & 65,0 \\
\hline Porcentaje de mujeres & 32,0 & 48,0 & 14,0 & 22,5 \\
\hline Edad (media) & 47,6 & $52,6^{\star *}$ & 49,6 & 47,6 \\
\hline Porcentaje con estudios universitarios & 89,6 & 96,0 & 71,8 & $47,5^{\star \star \star}$ \\
\hline \multicolumn{5}{|l|}{ POI procedentes de: } \\
\hline Europa & - & 28,0 & - & 67,5 \\
\hline América & - & 68,0 & - & 20,0 \\
\hline África & - & 4,0 & - & 10,0 \\
\hline Asia & - & - & - & - \\
\hline Oceania & - & - & - & 2,5 \\
\hline Porcentaje de electos por primera vez & 47,0 & $24,0^{\star \star}$ & 50,4 & 40,0 \\
\hline Años previamente en el Parlamento (media) & 8,4 & $13,5^{\star \star \star}$ & 7,7 & 7,6 \\
\hline $\begin{array}{l}\text { Porcentaje de electos desde el comienzo } \\
\text { de la legislatura }\end{array}$ & 86,4 & 92,0 & 95,7 & 95,0 \\
\hline $\begin{array}{l}\text { Porcentaje en el Parlamento hasta finales } \\
\text { de la legislatura }\end{array}$ & 86,5 & 84,0 & 95,6 & 92,5 \\
\hline $\begin{array}{l}\text { Porcentaje en comisiones parlamentarias relacionadas } \\
\text { con la inmigración }\end{array}$ & 51,7 & $32,0^{\star \star}$ & 43,8 & 40,0 \\
\hline Porcentaje con roles en comisiones parlamentarias & 59,1 & $36,0^{\star *}$ & 14,2 & 15,0 \\
\hline $\begin{array}{l}\text { Porcentaje con roles parlamentarios durante } \\
\text { la legislatura }\end{array}$ & 31,4 & $56,0^{\star *}$ & 11,5 & 5,0 \\
\hline $\begin{array}{l}\text { Porcentaje con cargos electos previos } \\
\text { (local, regional, UE) }\end{array}$ & 53,2 & 44,0 & 42,9 & 35,0 \\
\hline $\begin{array}{l}\text { Porcentaje con cargos gubernamentales previos } \\
\text { a nivel nacional o autonómico }\end{array}$ & 13,8 & $40,0^{\star *}$ & 8,7 & 5,0 \\
\hline $\begin{array}{l}\text { Porcentaje con cargo político en la organización } \\
\text { nacional del partido }\end{array}$ & 33,0 & $72,0^{\star \star \star}$ & 29,9 & 40,0 \\
\hline Años de afiliación al partido (media) & 15,0 & $20,1^{\star \star}$ & 6,3 & 6,0 \\
\hline Porcentaje en partidos de centroizquierda & 48,6 & 32,0 & 34,8 & $67,5^{\star \star \star}$ \\
\hline \multicolumn{5}{|l|}{ Fuente: elaboración propia a partir de los datos de Pathways. } \\
\hline \multicolumn{5}{|c|}{ *** Diferencias de medias y de porcentajes estadísticamente significativos al $99 \%$. } \\
\hline \multicolumn{5}{|c|}{ ** Diferencias de medias y porcentajes estadísticamente significativos al 95\%. } \\
\hline \multicolumn{5}{|c|}{$\begin{array}{l}\text { En las parejas mixtas uno de los progenitores tenía nacionalidad española o italiana desde el nacimiento. } \\
\text { La distribución por regiones de origen se refiere bien al país de nacimiento o nacionalidad del diputado o } \\
\text { la diputada (para primeras generaciones), bien al origen de los padres (para segundas generaciones). El } \\
\text { número de años previamente en el Parlamento se refiere al tiempo durante el cual el diputado o la diputada } \\
\text { ha estado en el Parlamento antes de cada legislatura analizada. }\end{array}$} \\
\hline
\end{tabular}


ciento en Italia descienden de parejas mixtas. Como cabía esperar, los niveles de representación varían sustancialmente entre los distintos colectivos. En este sentido, nuestra hipótesis inicial era que la distribución de diputados y diputadas inmigrantes por grupos específicos reflejaría, en cierto modo, el peso demográfico de dichos colectivos, su perfil migratorio, así como su potencial identificación como minorías «visibles».

Los datos para España confirman que la mayoría proceden de América Latina, en particular de Argentina y Cuba. Sin embargo, estas comunidades no constituyen los colectivos latinoamericanos más numerosos en España, sino que reflejan los flujos iniciales que entraron en el país durante las décadas de 1970 y 1980. En cambio, ningún diputado o diputada de origen inmigrante procede de Rumanía o Marruecos, colectivos que constituyen una proporción considerable de la población inmigrante residente en España (el 32 por ciento en 2015). En Italia, la mayoría de los diputados y diputadas de origen inmigrante proceden de otros países europeos (España, Francia, Grecia, Reino Unido, Polonia, Croacia, Eslovenia, Suiza y Lituania), mientras que el resto se distribuye entre África (Marruecos, Congo, Argelia), América Latina (República Dominicana y Argentina), Australia, EE.UU. y Jordania. En Italia, hasta las elecciones de 2006, casi todos los y las representantes de origen inmigrante procedían de otros países europeos. De este modo, los colectivos africanos y latinoamericanos obtienen representación en el Parlamento italiano solo en fechas más recientes. Sin embargo, ningún diputado o diputada es de origen albanés o rumano, pese a su notable presencia demográfica (el 33 por ciento de la población inmigrante en 2015).

Los datos sobre trayectorias políticas muestran que en España la mayoría de los diputados y las diputadas de origen inmigrante cuentan con una considerable experiencia parlamentaria, mientras que en Italia el 40 por ciento entraron en el Parlamento por primera vez durante las legislaturas analizadas. $\mathrm{Al}$ igual que quienes no son de origen inmigrante, casi todos los diputados y las diputadas inmigrantes en España e Italia permanecieron en el Parlamento desde el principio hasta el final de las legislaturas analizadas, lo que indica que ocupaban posiciones relativamente «seguras» en las listas electorales de sus partidos respectivos. En España, la media de años que dichos diputados y diputadas inmigrantes han pasado en el Congreso antes de cada legislatura analizada fue mayor que para quienes no eran de origen inmigrante.

Los diputados y las diputadas de origen inmigrante cuentan también con una notable experiencia previa en otros cargos electos. En ambos países, la mayoría han ostentado cargos electos a nivel municipal, aunque ninguno (en España) o muy pocos (en Italia) han sido miembros del Parlamento Europeo. En España, una proporción considerable de los diputados y de las diputadas de origen inmigrante también ha formado parte de ejecutivos nacionales o autonómicos, en porcentajes incluso más elevados que los diputados y las diputadas que no son de origen inmigrante. En general, por tanto, observamos una pauta clara que distingue el proceso de reclutamiento de POI en ambos países, con los representantes españoles de origen inmigrante mostrando un 
cursus honorum mucho más largo y una experiencia política muy consolidada antes de llegar al Congreso de los Diputados.

En cuanto a la afiliación partidista, la mayoría de los diputados y de las diputadas de origen inmigrante identificados en ambos países fueron nominados en las listas de los partidos que obtuvieron el mayor número de escaños. En Italia, la mayoría estaba en las filas de partidos de centroizquierda, tal y como esperábamos inicialmente. Durante las legislaturas analizadas, los principales partidos de centroizquierda en cada legislatura — PDS, DS y PD- siempre han tenido al menos dos diputados y/o diputadas de origen inmigrante. Para la mayoría de estas legislaturas, una parte considerable de las personas representantes de origen inmigrante provenían del PRC, y durante la legislatura 2006-2008, por ejemplo, más de un 40 por ciento de todos los representantes de origen inmigrante pertenecían este partido. No obstante, el centroderecha - especialmente, FI y AN — también ha proporcionado diputados y diputadas de origen inmigrante, y más de la mitad de las personas representantes inmigrantes para la legislatura 2008-2013 eran afiliadas al PDL.

Sin embargo, nuestros datos para España contradicen claramente la hipótesis de que los partidos de centroizquierda incluirían más diputados y diputadas inmigrantes que los partidos de centroderecha. A la luz de los resultados, casi el 70 por ciento de los diputados y diputadas de origen inmigrante en el Congreso fueron elegidos en las listas del PP. Hasta 2011, el PSOE siempre tuvo al menos un diputado o una diputada de origen inmigrante en cada legislatura analizada, mientras que el PP registró un mínimo de dos diputados y/o diputadas inmigrantes en cada legislatura. De hecho, todas las personas representantes inmigrantes del período legislativo 2011-2015 y la mitad de aquellas elegidas para la legislatura 2016-2016 estaban afiliadas al Partido Popular.

En España, la mayoría de estos diputados y diputadas de origen inmigrante eran miembros de los órganos ejecutivos nacionales de sus partidos, y estaban afiliados a ellos por un período de tiempo incluso más largo que los diputados y las diputadas que no tienen origen inmigrante. En Italia, la proporción de representantes electos de origen extranjero con cargos en las organizaciones nacionales de sus partidos es sustancialmente menor, sin diferencias notables con respecto a las personas representantes no inmigrantes. Además, los diputados y diputadas de origen inmigrante identificados en Italia cuentan con una antigüedad de afiliación en los partidos en cuyas listas fueron elegidos similar a la del resto de diputados y diputadas.

Un último aspecto que cabe destacar es que pocos diputados y diputadas inmigrantes han formado parte de comisiones parlamentarias con mayor probabilidad de tratar temas relacionadas con la inmigración o la integración de los inmigrantes. En España, por ejemplo, el porcentaje de quienes han pertenecido a este tipo de comisiones es aún más bajo que entre quienes no son de origen inmigrante. Por otra parte, aunque en Italia muy pocos representantes de origen extranjero han asumido algún rol parlamentario durante las legislaturas analizadas, en España casi el 60 por ciento de ellos ha ocupado alguna función de liderazgo parlamentario, y su proporción duplica la tasa observada para quienes no son de origen inmigrante. 
Todos estos resultados apuntan a estrategias distintas por parte de los partidos españoles e italianos a la hora de reclutar candidatos y candidatas de origen inmigrante para las listas a la cámara baja de sus países respectivos. Mientras que los partidos italianos parecen buscar explícitamente personas que representen ciertos grupos demográficos, siempre y cuando cuenten con un mínimo de experiencia política similar al de muchos otros diputados y diputadas, los partidos españoles claramente no parecen ofrecer facilidades y parecen requerir un perfil incluso más experimentado que el del resto de representantes.

\section{Conclusiones}

El principal objetivo de este estudio ha sido el de profundizar en una cuestión poco explorada hasta la actualidad: la representación política de las personas de origen inmigrante en España e Italia, dos países que han experimentado flujos migratorios muy intensos durante las últimas décadas. Tanto España como Italia destacan como estudios de caso muy interesantes a la hora de analizar las respuestas de los partidos hacia la inclusión de las POI en el sistema político, particularmente en un contexto en el que las demandas crecientes de representación política de la población nacida en el extranjero han ido acompañadas de una progresiva preocupación social sobre la inmigración. Dado que ambos países han empezado a recibir flujos migratorios sustanciales en fechas relativamente recientes y teniendo en cuenta el largo período de residencia previa impuesto en el proceso de naturalización que da acceso al derecho de sufragio pasivo para elecciones generales, esperábamos que los partidos españoles e italianos respondieran gradualmente a la demandas de incorporación de estos nuevos residentes en los parlamentos, particularmente desde mediados o finales de la primera década del siglo XXI. Sin embargo, también esperábamos que dicha inclusión de diputados y diputadas de origen inmigrante fuera más bien simbólica, como señal de adaptación de los partidos hacia los cambios demográficos en ambos países.

Nuestros resultados son consistentes con ese pronóstico inicial, al mostrar que las POI han alcanzado niveles muy bajos de representación política en estos países del sur de Europa, con una presencia muy limitada en los parlamentos nacionales y regionales en ambos. Vistos los datos, un número muy reducido de sus diputados y diputadas son de origen inmigrante y, dado el peso demográfico considerable de la población nacida en el extranjero en ambos países, los porcentajes de diputados y diputadas de origen inmigrante que hemos identificado están muy por debajo de las expectativas de representación "perfecta» basadas en una interpretación inclusiva del demos.

Por otra parte, los niveles de representación alcanzados por las POI son bastante similares en estos dos países (y algo más elevados en Italia que en España para legislaturas más recientes), pese a los flujos migratorios más intensos hacia España, las actitudes más favorables de los españoles hacia la inmigración y la ausencia de fuertes partidos antiinmigración en España en comparación con Italia. 
La presencia limitada de POI en los parlamentos de España e Italia puede entenderse mejor si consideramos el papel clave que desempeñan los partidos a la hora de decidir quién figura en las listas electorales. Como hemos mostrado a lo largo del trabajo, hay una serie de ventajas y desventajas que los partidos pueden anticipar en relación a la inclusión de POI en sus listas electorales. La nominación de POI podría beneficiar a los partidos, ya que les permitiría mostrar a los votantes su capacidad de responder adecuadamente a los fuertes cambios demográficos, además de ofrecerles la posibilidad de atraer a un nuevo nicho de votantes —el electorado inmigrante—, que todavía es bastante maleable en términos de lealtades de voto. Sin embargo, las pocas presiones electorales que los partidos españoles e italianos han recibido para incluir a POI se han visto acompañadas por una opinión pública cada vez más restrictiva acerca de la inmigración.

En este contexto, la decisión de los partidos de reclutar candidatos y candidatas inmigrantes podría suponer asumir un coste electoral. Es más, dada la intensificación de las actitudes negativas hacia la inmigración en ambos países, también esperábamos que si los partidos finalmente decidían presentar candidatos y candidatas inmigrantes, su preferencia inicial hubiera sido nominar minorías «invisibles» como estrategia para evitar las reacciones negativas por parte del público en general. Nuestros resultados son consistentes con esta hipótesis, ya que muy pocos diputados y diputadas de origen inmigrante pertenecen a minorías «visibles» en España y en Italia.

Sin embargo, los datos apoyan solo algunas de nuestras hipótesis acerca de la diferencia en los niveles de representación política de distintos colectivos inmigrantes. La mayoría de las personas representantes de origen inmigrante en España proceden, tal como esperábamos, de América Latina, aunque no necesariamente de las comunidades latinoamericanas más numerosas residentes en el país. Por otro lado, los inmigrantes comunitarios no han conseguido asegurar su representación política en España. En Italia, más de la mitad de los diputados y diputadas de origen inmigrante proceden de otros países europeos, aunque la comunidad albanesa o la rumana no han logrado escaños en el Parlamento italiano.

Por último, también esperábamos que, dados los pocos incentivos electorales que los partidos tienen a la hora de presentar candidatos y candidatas inmigrantes, esta nominación simbólica sería más frecuente entre los partidos de centroizquierda que entre los partidos de centroderecha. Sin embargo, los resultados obtenidos no apuntan hacia un efecto sistemático de la posición ideológica de los partidos sobre los niveles de representación descriptiva de las POI, porque, tal como se ha mostrado a lo largo del estudio, aunque la distribución de los diputados y de las diputadas de origen inmigrante por afiliación partidista es consistente con la hipótesis inicial en Italia, en España la mayoría de las personas representantes de origen inmigrante identificadas en nuestra base de datos estaban afiliadas al PP, contradiciendo nuestra hipótesis inicial.

En conclusión, tanto los partidos españoles como los italianos no han respondido de manera ágil a los considerables cambios demográficos experimen- 
tados en sus sociedades respectivas. No obstante, dada la configuración de la competición partidista - con una mayor presencia de partidos antiinmigración-y de la opinión pública — con poblaciones con actitudes ligeramente más restrictivas-, los partidos italianos han demostrado ser algo más inclusivos en el corto plazo que los españoles. En buena medida, nuestros resultados sugieren que los partidos de centroizquierda españoles han sido especialmente lentos y reacios a incorporar de manera adecuada a la nueva ciudadanía, tanto en la política nacional como en la autonómica, al menos cuando los comparamos con sus homólogos italianos.

\section{Referencias bibliográficas}

BAKKER, Ryan; De VRIES, Catherine; EDWARdS, Erica; HoOGHE, Liesbet; Jolly, Seth; Marks, Gary; Polk, Jonathan; RovnY, Jan; STEEnBERgEN, Marco y Vachudova, Milada Anna (2012). «Measuring party positions in Europe: The Chapel Hill expert survey trend file, 1999-2010». Party Politics, 21(1), 143-152. <https://doi.org/10.1177/1354068812462931>

BIRD, Karen (2005). «The political representation of visible minorities in electoral democracies: A comparison of France, Denmark, and Canada». Nationalism and Ethnic Politics, 11(4), 425-465. <https://doi.org/10.1080/13537110500379211>

Bird, Karen; SAalfeld, Thomas y WÜsT, Andreas M. (2011). «Ethnic Diversity, Political Participation and Representation: A Theoretical Framework». En: BIRD, Karen; SAAlfeld, Thomas y WÜst, Andreas M. (eds.). The Political Representation of Immigrants and Minorities: Voters, Parties and Parliaments in Liberal Democracies. Londres: Routledge.

BloemraAd, Irene (2013). «Accessing the Corridors of Power: Puzzles and Pathways to Understanding Minority Representation». West European Politics, 36(3), 652-670. <https://doi.org/10.1080/01402382.2013.773733>

Cappiali, Teresa Maria (2015). Activism and Participation Among People of Migrant Background: Discourses and Practices of Inclusiveness in Four Italian Cities Tesis doctoral. Recuperado de <https://papyrus.bib.umontreal.ca/xmlui/bitstream/ handle/1866/13579/Cappiali_Maria\%20Teresa_2015_these.pdf?sequence=2 $>$.

Caul, Miki (1999). "Women's Representation in Parliament: The Role of Political Parties». Party Politics, 5(1), 79-98. <https://doi.org/10.1177/1354068899005001005>

Cebolla, Héctor y González, Amparo (2008). La inmigración en España (20002007): De la gestión de los flujos a la integración de los inmigrantes, Cuadernos y Debates. Madrid: Centro de Estudios Políticos y Constitucionales.

Celis, Karen; Eelbode, Floor y Wauters, Bram (2013). «Visible Ethnic Minorities in Local Political Parties: A Case Study of Two Belgian Cities (Antwerp and Ghent)». Politics, 33(3), 160-171. <https://doi.org/10.1111/1467-9256.12018>

CiorneI, Irina (2014). «The Political Candidancy of EU Migrants in their European Countries of Residence: The Case of the British and Romanians Standing in Spanish Local Elections». Journal of Ethnic and Migration Studies, 40(9), 1375-139. <https://doi.org/10.1080/1369183x.2013.857594> 
Claro da FonsECA, Sara (2011). «New citizens - new candidates?: Candidate selection and the mobilization of immigrant voters in German elections». En: BIRD, Karen; SAAlfeld, Thomas y Wüst, Andreas M. (eds.). The Political Representation of Immigrants and Minorities: Voters, Parties and Parliaments in Liberal Democracies. Londres: Routledge.

Colombo, Asher y Sciortino, Giuseppe (2004). «Italian immigration: The origins, nature and evolution of Italy's migratory systems». Journal of Modern Italian Studies, 9(1), 49-70. <https://doi.org/10.1080/1354571042000179182>

Eurostat (2011). Migrants in Europe: A statistical portrait of the first and second generation. Recuperado de <http://ec.europa.eu/eurostat/en/web/products-statisticalbooks/-/KS-31-10-539>.

- (2015). Database Population and Social Conditions. Recuperado de <http:// ec.europa.eu/eurostat/data/database>.

JANOSCHKA, Michael (2010). «Between mobility and mobilization: Lifestyle migration and the practice of European identity in political struggles». The Sociological Review, 58, 270-290. <https://doi.org/10.1111/j.1467-954x.2011.01973.x>

INE (2015). Estadistica del Padrón Continuo. Recuperado de <http://www.ine.es/ dyngs/INEbase/es/operacion.htm?c=Estadistica_C\&cid=1254736177012\&men $\mathrm{u}=$ ultiDatos\&idp $=1254734710990>$.

ISTAT (2015). Popolazione e Famiglie. Recuperado de <http://www.istat.it/it/popolazione-e-famiglie>.

MÉNDEZ LAGO, Mónica (2010). «La participación de los extranjeros comunitarios en las elecciones municipales en España: 1999, 2003 y 2007». En: MOYA MALAPEIRA, David y VIÑAs FERRER, Alba (eds.). Sufragio y participación política de los extranjeros extracomunitarios en Europa. Barcelona: Fundació Carles Pi i Sunyer.

MonZINI, Paola (2008). «Il traffico di migranti per mare verso l'Italia: Sviluppi recenti (2004-2008)». CeSPI Working Papers, 43/2008. Recuperado de <http://www.cespi. it/WP/WP43-Traffico-Monzini.pdf>.

Morales, Laura; Anduiza, Eva; Rodríguez, Elisa y San Martín, Josep (2010). "Comportamiento electoral y acción política». En: MOYA MalapeIra, David y VINAAS FERRER, Alba (eds.). Sufragio y participación política de los extranjeros extracomunitarios en Europa. Barcelona: Fundació Carles Pi i Sunyer.

Morales, Laura; Anduiza, Eva; Rodríguez, Elisa y San Martín, Josep (2008). "Capital social, pautas identitarias y actitudes hacia "los otros": La incorporación cívica de la población de origen inmigrante en Barcelona y Madrid». Panorama Social, 8, 119-142.

Morales, Laura y GiUgni, Marco (eds.) (2011). Social capital, political participation and migration in Europe: Making multicultural democracy work? Basingtoke: Palgrave.

Morales, Laura; PARdos-Prado, Sergi y Ros, Virginia (2014). «Issue emergence and the dynamics of electoral competition around immigration in Spain». Acta Politica, 50(4), 461-485. <https://doi.org/10.1057/ap.2014.33>

MORALES, Laura y Ros, Virginia (2012). «La politización de la inmigración en España en perspectiva comparada». Documentos CIDOB, 25. Recuperado de <http://www. cidob.org/es/publicaciones/series_pasadas/documentos/migraciones/la_politizacion_de_la_inmigracion_en_espana_en_perspectiva_comparada>. 
Morales, Laura y SAN MARTín, Josep (2011). «¿Cómo votarían los inmigrantes?». Zoom Político. Recuperado de <http://www.falternativas.org/content/download/17186/487661/version/5/file/zoomPol_02_04.pdf>.

Morales, Laura; Vintila, Daniela; Geese, Lucas; MÜgge, Liza; VAn der Pas, Daphne y VAN DE WARDT, Marc (2017). "Codebook and data collection guidelines of work package 1 on descriptive political representation in national parliaments of the project Pathways to Power». Leicester: University of Leicester. $<$ http://www.pathways.eu> y <https://dataverse.harvard.edu/dataverse/WP1Descriptives.

Moya Malapeira, David (2010). «Regulación del derecho de sufragio de los extranjeros en España y los mecanismos alternativos de participación política». En: MoYA MALAPEIRA, David y VIÑAS FERRER, Alba (eds.). Sufragio y participación política de los extranjeros extracomunitarios en Europa. Barcelona: Fundació Carles Pi i Sunyer.

Norris, Pippa (2006). "The Impact of Electoral Reform on Women's Representation». Acta Politica, 41(2), 197-213. $<$ https://doi.org/10.1057/palgrave.ap.5500151>

OECD (2015). International Migration Database. Recuperado de <https://stats.oecd. org/Index.aspx? DataSetCode=MIG>.

Pérez-Nievas, Santiago; Vintila, Cristina Daniela; Morales, Laura y Paradés, Marta (2014). La representación politica de los inmigrantes en España: Un análisis empírico. Madrid: Centro de Investigaciones Sociológicas.

Pitkin, Hanna Fenichel (1967). The Concept of Representation. Berkeley: University of California Press.

RoS, Virginia y MORALES, Laura (2015). «The politicisation of immigration in Spain». En: VAn DER Brug, Wouter; D’Amato, Gianni; BerKhout, Joost y RuEdin, Didier (eds.). The politicisation of migration. Abingdon: Routledge.

Santolaya, Pablo y Díaz Crego, Maria (2008). El sufragio de los extranjeros: Un estudio de derecho comparado. Madrid: Centro de Estudios Políticos y Constitucionales.

TINTORI, Guido (2013). «Access to electoral rights: Italy». Informe del EUDO Citizenship Observatory. Recuperado de <http://eudo-citizenship.eu/admin/?p=file $\&$ appl=countryProfiles\&f=133-Italy-FRACIT.pdf $>$.

VEIKOU, Mariangela y TRIANDAFYLLIDOU, Anna (2001). «Immigration policy and its implementation in Italy, a report on the state of the art». Report prepared for the research project Does implementation matter. Mediterranean Migration Observatory. Recuperado de <http://www.mmo.gr/pdf/library/Italy/triandaf.pdf>.

Venturini, Alessandra (2004). Postwar migration in southern Europe, 1950-2000: An economic analysis. Nueva York: Cambridge University Press.

VINTILA, Cristina Daniela (2015). The European citizenship and the electoral rights of non-national EU citizens in the EU Member States. Madrid: Universidad Autónoma de Madrid. Tesis doctoral.

Zapata-BARRERO, Ricard y BurChIANTI, Flora (2014). Openness of political parties to immigrants and TCN in Spain. Informe final del proyecto DIVPOL. Recuperado de <http://www.cjd-eutin.eu/fileadmin/assets/eutin/Downloads/Country_Reports/ DIVPOL_Final_Report_ES.pdf>. 